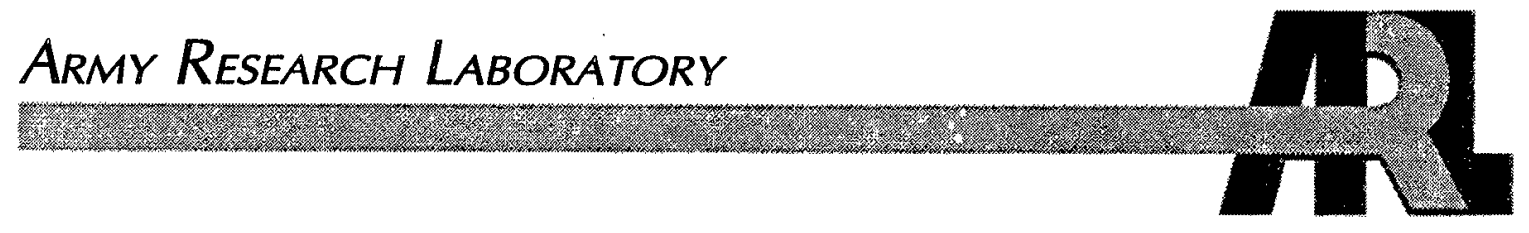

\title{
Upscaled Self-Propagating High-Temperature Synthesis (SHS)/Dynamic Compaction Processing
}

\author{
by R. M. Cooper
}

ARL-CR-439
prepared by
Xform, Inc.
100 N. Mohawk Street
P.O. Box A9
Cohoes, NY 12047-1754
under contract
DAAA15-91-C-0071

Approved for public release; distribution is unlimited. 
The findings in this report are not to be construed as an official Department of the Army position unless so designated by other authorized documents.

Citation of manufacturer's or trade names does not constitute an official endorsement or approval of the use thereof.

Destroy this report when it is no longer needed. Do not return it to the originator. 


\section{Abstract}

Titanium carbide $(\mathrm{TiC})$ and titanium diboride $\left(\mathrm{TiB}_{2}\right)$ ceramics were formed from elemental powders using a Gleeble 1500 dynamic thermomechanical process simulator. In the first step of a two-step process, a self-propagating high-temperature synthesis (SHS) reaction was initiated by the passage of an electric current through the powdered green body. The temperature of the body was maintained at about $800^{\circ} \mathrm{C}$, and the reaction rate was controlled by the application of a pressure of about $35 \mathrm{MPa}$. As verified by $\mathrm{x}$-ray diffraction analysis, this procedure resulted in complete conversion from reactants into products having a range of densities from 72 to $75 \%$ of theoretical. In the second step, the current was increased to raise the temperature of the material, thereby sintering and densifying the product. TiC with $3 \mathrm{wt} . \%$ nickel (Ni) was sintered to 95 to $98 \%$ of theoretical density, while $\mathrm{TiC}$ without $\mathrm{Ni}$ was sintered to $90 \%$ theoretical density. Although $\mathrm{TiB}_{2}$ was successfully converted, efforts to fully densify the product were hindered by the limitations of the Gleeble 1500 . The effects of the current and pressure levels on the product density and microstructure were examined. The advantages and limitations of this process are also discussed. 


\section{Acknowledgments}

Xform would like to express its gratitude to Professor Roger Wright and the High Temperature Technology Program at Rensselaer, and to Duffers Scientific Associates for their contributions throughout the effort. Xform acknowledges the contributions and efforts of Dr. Theodore Schurman, Dr. Wojciech Misiolek, and Mr. Nicholas Sopchak of the Rensselaer Polytechnic Institute research team. Gratitude is also expressed to Professor Randall German and Mr. Karl Shaw for their contributions. 
INTENTIONALLY LEFT BLANK. 


\section{Table of Contents}

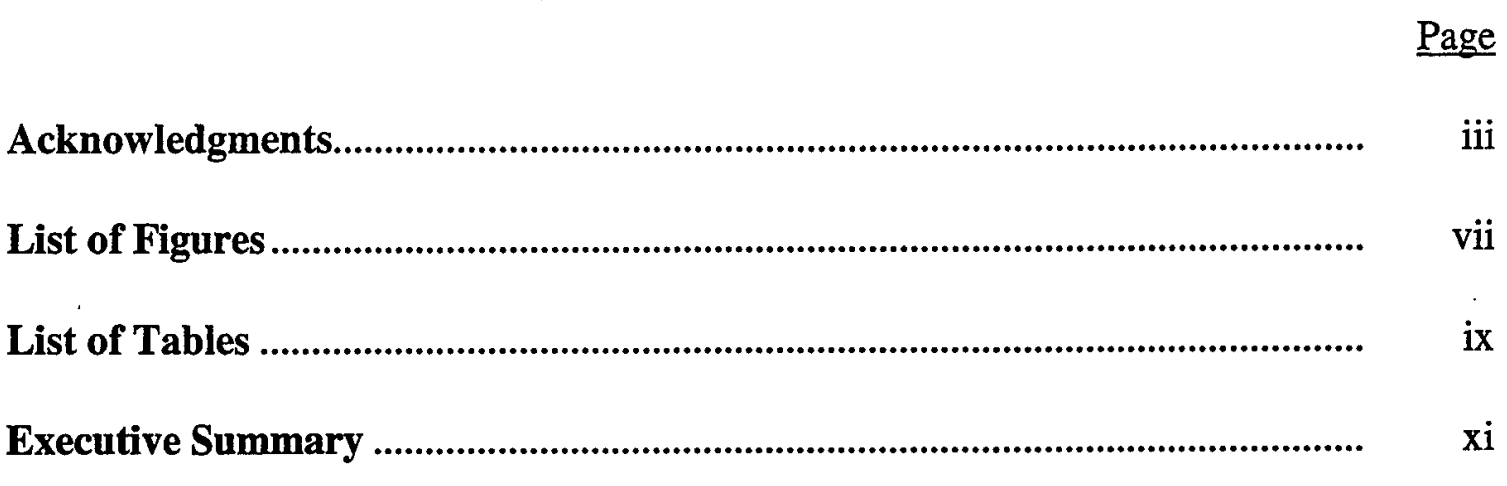

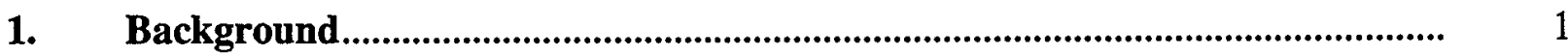

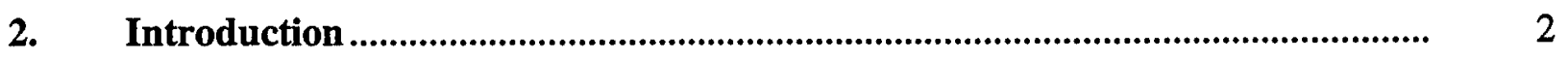

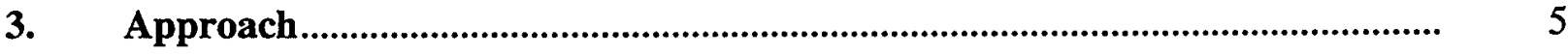

4. Reactive Sintering/Dynamic Compaction ................................................ 9

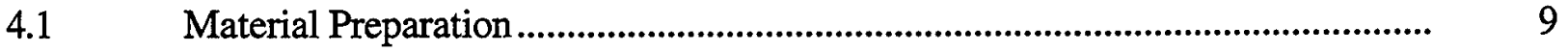

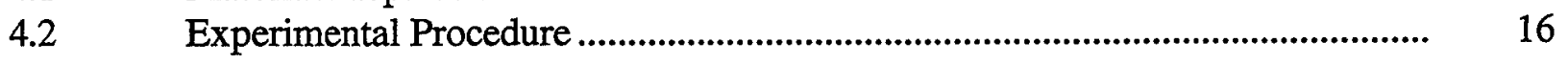

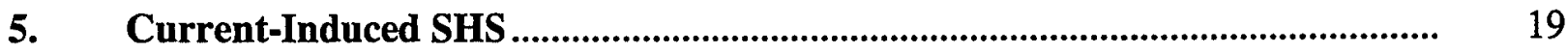

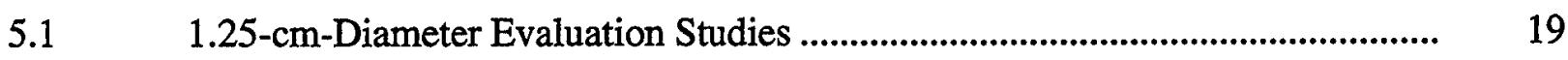

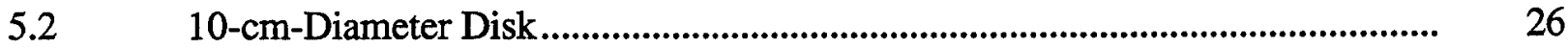

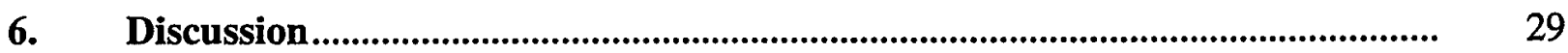

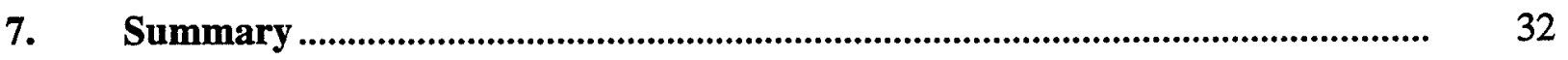

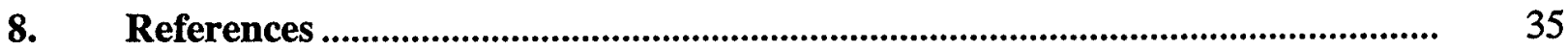

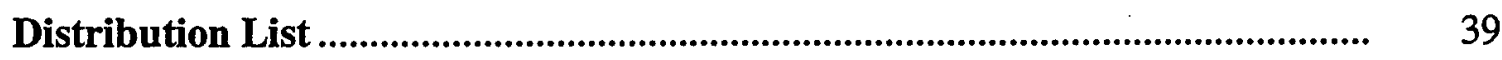

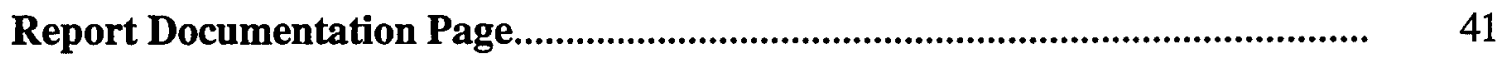


INTENTIONALLY LEFT BLANK. 


\section{List of Figures}

Figure

Page

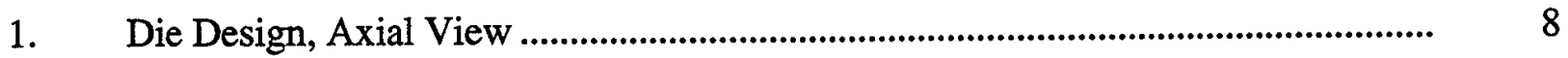

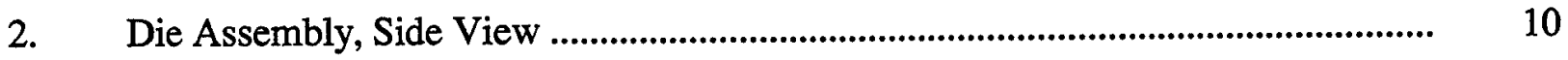

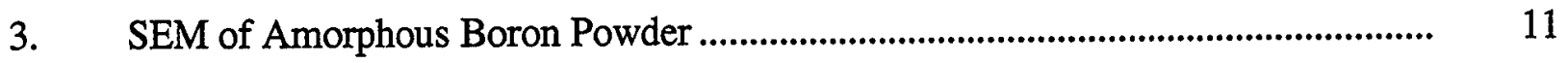

4. SEM of Crystalline Boron Powder................................................................... 11

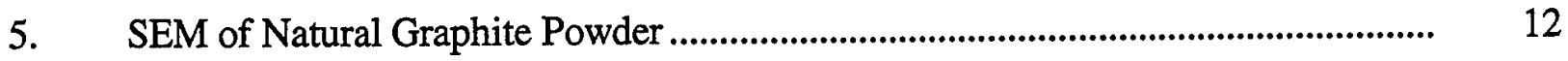

6. SEM of Synthetic Graphite Powder .................................................................. 12

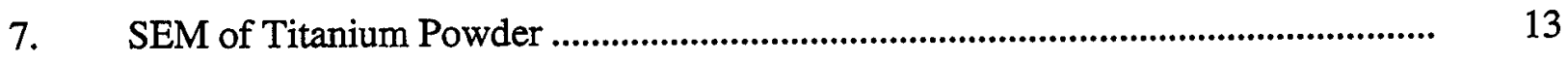

8. Particle Size Distribution for Amorphous Boron ................................................ 14

9. Particle Size Distribution for Crystalline Boron ............................................... 14

10. Particle Size Distribution for Synthetic Graphite ................................................ 15

11. Particle Size Distribution for Natural Graphite ................................................... 15

12. Particle Size Distribution for Titanium ............................................................ 16

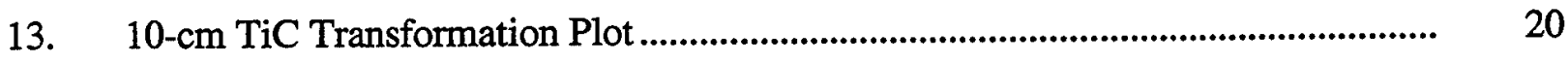

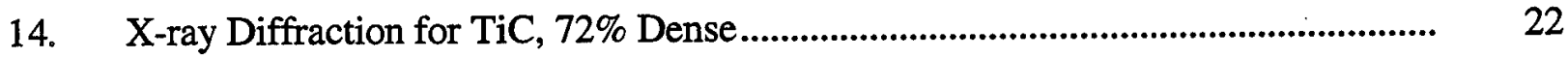

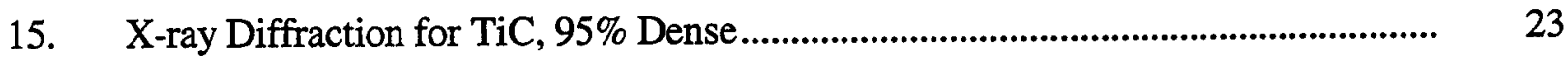

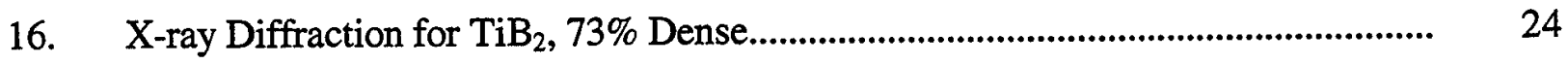

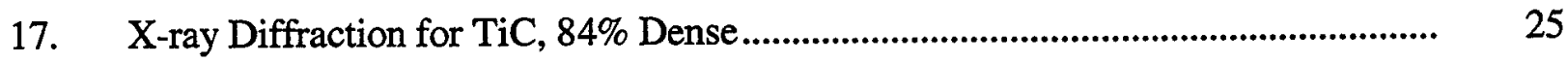

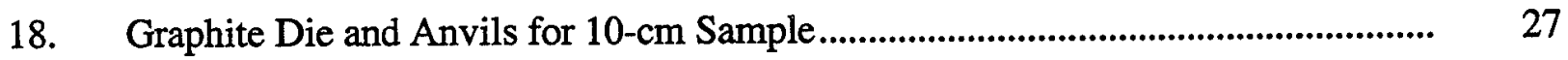

19. Sample A5 Microstructure, $72 \%$ Dense ............................................................. 31 
20. Sample A38 Microstructure, 95\% Dense ................................................................. 31

21. Sample A38 Microstructure, 95\% Dense; Enlarged View .......................................... 32 


\section{List of Tables}

Table $\quad \underline{\text { Page }}$

1. Listing of Powders Employed in Study.................................................................... 10

2. Mean Particle Sizes of Powder...............................................................................

3. Powder Amounts for Scale-Up to 10-cm-Diameter Sample ........................................ 27

4. Hot Pressing Data for 10-cm-Diameter Sample............................................................. 28

5. Density Measurements ( $\mathrm{TiC} 3$ wt.-\% Ni)................................................................. 30 
INTENTIONALLY LEFT BLANK. 


\section{Executive Summary}

Titanium carbide $(\mathrm{TiC})$ and titanium diboride $\left(\mathrm{TiB}_{2}\right)$ ceramics were formed from elemental powders by self-propagating high-temperature synthesis (SHS) by passing electrical current through the compact while the pressed powders were under a compressive load. With this developed technique, the reaction occurs in a controlled and steady manner allowing the graphite container surrounding the powders to remain at a low overall temperature during the reaction (e.g., $800^{\circ} \mathrm{C}$ for TiC). Pressure is applied during the reaction to aid densification and to achieve the controlled SHS reaction. The process works by passing electrical current through the conductive powders that are contained within a graphite tube. Extremely high current densities and heating are achieved locally at particle interfaces resulting from the high electrical resistance of the particle interfaces. This heating is sufficient to initiate the reaction locally for titanium (Ti) and graphite, or for $\mathrm{Ti}$ and boron (B), to form $\mathrm{TiC}$ or $\mathrm{TiB}_{2}$, with the resultant release of heat. With this electrical current-induced SHS approach, the large, violent exothermic reaction associated with allowing the entire sample to reach the initiation temperature and to react to form a combustion synthesized product is avoided. When pressure is applied during current-induced SHS, the reaction will not self-propagate throughout the sample; the applied pressure increases thermal conduction and heat is extracted. The SHS reaction in this mode therefore stagnates, since this heat extraction keeps the neighboring elements from reaching the initiation temperature for compound formation and from reacting exothermically. As current continues to pass through the sample, new initiation sites continue to develop and react until all of the elemental powders have been transformed. Since outgassing associated with the exothermic transformation occurs locally during this method, there is time for the gas to escape from the compact and to not be entrapped. And because the reaction occurs stepwise and locally, there is no large outgassing volume; the vacuum level decreases within the reaction chamber, but vacuum is not lost completely as would be when the initiation temperature is reached in traditional SHS.

This approach provides an efficient and inherently safe process for forming materials by SHS. Because the elemental powders may be transformed to the product without the large release of heat 
and associated tremendous gas liberation, a wider range of lower cost materials for containing the reaction is possible.

In this 6-mo effort, the electrical current-induced process was developed to form $\mathrm{TiC}$ and $\mathrm{TiB}_{2}$ ceramics by SHS reactions in a controlled and safe manner by initiating the reaction locally at the high-resistance particle interfaces. Both $\mathrm{TiC}$ and $\mathrm{TiB}_{2}$ 1.25-cm-diameter samples were formed from the elemental powders employing the two-step technique. As practiced, the transformation occurs first at roughly $800^{\circ} \mathrm{C}$ and then the temperature is raised to densify the sample. Following transformation, the product density is $72-75 \%$ of theoretical for the samples when $35 \mathrm{MPa}(5 \mathrm{ksi})$ of pressure is applied. The current level is then raised to heat the sample to densify the transformed product. Densities of 95-98\% of theoretical density were achieved for TiC with 3 wt.-\% nickel (Ni) addition after producing the product at a temperature of $800^{\circ} \mathrm{C}$ and then heating to $1,400^{\circ} \mathrm{C}$ for less than $15 \mathrm{~min}$ for densification. Without $\mathrm{Ni}$ addition, it was necessary to heat to $2,000^{\circ} \mathrm{C}$ following transformation to $\mathrm{TiC}$ and hold for under $15 \mathrm{~min}$ to reach high densities. Despite this, TiC without Ni was sintered only to $90 \%$ theoretical. This approach was then applied to the formation of a 10 $\mathrm{cm}$-diameter sample of TiC. A 2-kg mixture of Ti and graphite was transformed into TiC, keeping the temperature of the surrounding graphite tube from 700 to $900^{\circ} \mathrm{C}$. The Gleeble thermomechanical apparatus employed for performing the transformation was not capable of operating at the conditions required for achieving high density following the transformation step. The density of the 10-cm-diameter sample following transformation with the electrical process with an applied pressure of $2.8 \mathrm{MPa}(0.4 \mathrm{ksi})$ was $59 \%$ of theoretical. Formation of TiC was confirmed by $\mathrm{x}$-ray. To achieve further densification, the transformed sample was subsequently hot pressed at $2,000^{\circ} \mathrm{C}$ and $21 \mathrm{MPa}(3 \mathrm{ksi})$ at the General Electric Corporate Research and Development Center (Schenectady, NY). The final density after hot pressing was $84 \%$ of theoretical, and the microhardness measured $16.5 \mathrm{GPa}$. Ideally, the approach of passing additional current through the sample for sintering would have been employed to densify the 10-cm-diameter sample. However, constraints on the present apparatus could not be resolved in a timely and cost-effective manner. This necessitated the use of conventional hot pressing to densify the transformed TiC. Additionally, 
the use of current to sinter samples appears to aid densification and therefore appears superior to conventional furnace heating.

Additional work to be performed includes determining the effect of pressure on the density of the ceramic following transformation. A pressure of $2.8 \mathrm{MPa}$ on the 10-cm-diameter sample resulted in 59\% density after transformation, and $35 \mathrm{MPa}$ on the 1.25 -cm-diameter sample resulted in $73 \%$ density after transformation. The effects of higher pressures, such as $350 \mathrm{MPa}$, during the transformation need to be explored. It may be possible with higher applied pressures during the transformation to reduce this method to a one-step process for achieving high densities.

A Gleeble thermomechanical apparatus was employed in this research, but the equipment that would be used in a manufacturing environment would consist simply of a power supply system capable of supplying $450-800 \mathrm{~A} / \mathrm{cm}^{2}\left(3,000-5,000 \mathrm{~A} / \mathrm{in}^{2}\right)$, a vacuum system and chamber for carrying out the reaction, and a press for applying pressure. An apparatus would be built to supply current into a mixture of elemental powders while simultaneously applying pressure. Such a system would be inexpensive and would provide a safe and effective means for generating $\mathrm{TiC}$ and $\mathrm{TiB}_{2}$ ceramics by SHS.

Based on the current-induced process, an invention disclosure was filed by Dr. Theodore Schurman and Mr. Nicholas Sopchak entitled, "Low Enthalpy Power Controlled Synthesis." The process was demonstrated to synthesize $\mathrm{TiC}, \mathrm{TiB}_{2}$, and nickel aluminides (NiAl) from elemental powders while passing current through a powder compact while under pressure. 
INTENTIONALLY LEFT BLANK. 


\section{Background}

Research has demonstrated that the use of certain ceramics can enhance the performance of Army vehicle armors against attack by depleted uranium shells. Hard ceramic materials on the outside of tanks can prevent kinetic energy projectiles from coming into contact with the tank and rendering it inoperable. Use of these materials by the U.S. Army, however, is affected by their high cost. Producing monolithic low-porosity ceramics from titanium carbide (TiC) and titanium diboride $\left(\mathrm{TiB}_{2}\right)$ proves to be slow, expensive, inhomogeneous, and unreliable with standard powder processing approaches such as hot pressing.

Prior research at the U.S. Army Ballistic Research Laboratory (BRL) ${ }^{*}$ has shown that mixtures of elemental powders can be used to generate a ceramic compound through exothermic reactions such as self-propagating high-temperature synthesis (SHS). Along with compound synthesis, the excess heat from the reaction provides an opportunity for densification and net shaping through application of an external stress (e.g., Dynamic Compaction). In experiments conducted at BRL, the product after combustion synthesis (CS) is porous and is at a very high temperature, exceeding $2,500^{\circ} \mathrm{C}$; the porosity is eliminated by the use of a pressure wave that is generated using explosives. This two-step process consisting of first synthesizing a ceramic material and then consolidating to high density is referred to as Combustion Synthesis/Dynamic Compaction. This method has the potential of being a low-cost manufacturing process; the objective of this Phase I Small Business Innovation Research (SBIR) effort was to develop this method into a viable manufacturing process.

Reactive synthesis processing has been successively applied to the formation of intermetallics and ceramics [1-10]. The basic concept is to combine mixed elemental powders and to initiate a self-sustaining exothermic reaction. Generally, materials formed using this technique have low processing costs. However, many ceramics synthesized using reactive techniques are inherently

\footnotetext{
* The U.S. Army Ballistic Research Laboratory was deactivated on 30 September 1992 and subsequently became a part of the U.S. Army Research Laboratory (ARL) on 1 October 1992.
} 
resistant to high-temperature consolidation, and consequently, traditional, ceramic fabrication approaches prove less than ideal. Many of the reactively processed materials exhibit unique microstructures and properties, in part, due to their self-purification during the exothermic reaction. Reactive sintering techniques have progressed to the point where densities of $97 \%$ of theoretical may be obtained with intermetallics such as nickel aluminides (NiAl) [1-4], however, $\mathrm{TiC}$ and $\mathrm{TiB}_{2}$ have not been densified using reactive sintering processing. Near full density has been achieved through consolidation only, while the newly synthesized phase still contains its latent heat of reaction $[5,9$, 11-20].

This Phase I effort was intended to develop a cost-effective approach employed to mass produce ceramic components. The proposed approach included a thermomechanical simulator that would be used to heat the powder mixture by resistance heating to the initiation temperature through passage of current and then, at a predetermined time following CS, load the sample in compression at high strain rates to achieve dynamic compaction.

This approach has the advantage of separating the CS parameters (i.e., particle size, heating rate, green density, degassing, and so on) from the dynamic compaction parameters (i.e., time delay, pressure, strain rate, peak stress). This method provides a means for sequencing the reaction and compaction steps and providing the ability for direct current heating during compaction. The proposed approach of heating the compacted mixture of elemental powders by resistance heating is attractive because it has the advantages of being inherently safer, since there are no explosive materials involved, and of possessing rapid cycle times. A further objective of Phase I work would be to explore the several variables influencing reactive synthesis and dynamic compaction to isolate those conditions giving the most suitable products.

\section{Introduction}

As stated, the objective of this project was to study the feasibility of SHS followed by compaction to achieve high-density ceramic materials such as $\mathrm{TiC}$ and $\mathrm{TiB}_{2}$. The final product, in 
the form of cylindrical samples $10 \mathrm{~cm}$ in diameter $\times 2.5 \mathrm{~cm}$ thick, was expected to reach densities of $95 \%$ and $98 \%$ of the theoretical values for $\mathrm{TiC}$ and $\mathrm{TiB}_{2}$, respectively. The mechanical properties, measured by microhardness, had to be comparable to the values for the same materials manufactured by traditional hot pressing of $\mathrm{TiC}$ and $\mathrm{TiB}_{2}$ powders.

The thrust of this investigation was to develop an efficient low-cost potential manufacturing process for producing dense $\mathrm{TiC}$ and $\mathrm{TiB}_{2}$ ceramics employing SHS. Reactive sintering techniques have been successfully applied to the fabrication of several materials, such as borides, carbides, nitrides, silicides, intermetallics, and composites [21-25]. In some systems, the final density after reactive sintering is only on the order of $60 \%$ of theoretical density-utilization of additional densification techniques is necessary to increase the final density. To enhance the densification mechanism, experiments were planned employing reactive sintering with subsequent pressurization.

Underlying Principles. The CS of intermetallic compounds from mixed elemental powders is a new fabrication route for high-performance, high-temperature alloys. The SHS or reactive sintering reaction relies on the exothermic heat associated with compound formation to induce a transient liquid phase. Several compounds have been formed, including aluminides, silicides, hydrides, oxides, carbides, nitrides, and borides. Control over the transient liquid phase and the characteristics of the final product are possible through the heating rate, green density, degassing procedure, particle size, particle size ratio, powder homogeneity, and stoichiometry. For this effort, a large heat release from a combustion reaction was used to generate a thermal spike that forms a transient liquid phase. Consider a mixture of titanium (Ti) and carbon (C) powders. These powders will form a stoichiometric compound $\mathrm{TiC}$ with the release of heat $\mathrm{H}_{\mathrm{f}}$,

$$
\mathrm{Ti}+\mathrm{C}--->\mathrm{TiC}+\mathrm{H}_{\mathrm{f}} .
$$

The reaction from elemental powders results in the formation of a compound, in this case $\mathrm{TiC}$, and the release of excess heat. Such reactions are thermally activated events with the rate of reaction dependent on the temperature, 


$$
d y / d t=(1-y)^{n} k_{0} \quad \exp (-E / R T)
$$

where $\mathrm{y}$ is the fraction of reactant transformed, $\mathrm{t}$ is the time, $\mathrm{n}$ is the order of the reaction (usually 1 or 2), $k_{0}$ is the frequency factor, $E$ is the activation energy for the reaction, $R$ is the gas constant, and $\mathrm{T}$ is the absolute temperature. The reaction energy concept indicates that an activation energy $\mathrm{E}$ is needed to initiate diffusion across the interface between contacting particles. The probability that a given atomic vibration will gather sufficient energy to undergo such a step varies in proportion to $\exp (-\mathrm{E} / \mathrm{RT})$. However, once an atomic jump has become activated, there is a large energy return of $\mathrm{H}_{\mathrm{f}}$. Depending on the heat capacity of the material, this energy release creates a temperature increase, termed adiabatic heating. In turn, adiabatic heating leads to faster rates of reaction because of the strong rate sensitivity as expressed by the Arrhenius temperature dependence. This is especially true if a liquid should form. Such reactions are termed as autocatalytic, because when initiated, the reaction proceeds in a spontaneous manner without external heat input.

Generally, these reactions are known by such names as self-combustion, SHS, or reactive synthesis. Much research has occurred in the Soviet Union with such synthesis techniques. Reactive sintering is actually a variant of CS where simultaneous sintering densification is combined with the CS reaction. Reactive sintering occurs by mixing elemental powders in approximately the stoichiometric ratio. These powders are degassed to remove contaminants. The material is then reacted to induce formation of the compound. A transient liquid phase forms in most cases.

The parameters that influence CS fall into two categories: those that are inherent to the system thermodynamics (such as heat capacity, activation energy, and heat of formation) and those that are adjustable through the processing conditions (such as particle size, heating rate, green density, and composition). The heat of formation, initial compact temperature, and heat capacity of the materials determine the temperature rise in the reaction zone. The actual maximum temperature achieved is determined by an energy balance using the appropriate heat capacities and melting enthalpies. The adiabatic temperature, $T_{\mathrm{a}}$, represents the maximum possible temperature attainable in the reaction zone. It can be estimated using energy balance calculations, 


$$
\mathrm{H}_{\mathrm{f}}=\mathrm{C}_{\mathrm{p}} \mathrm{dT}+\mathrm{H}_{\mathrm{m}}
$$

with

$$
\mathrm{dT}=\mathrm{T}_{\mathrm{a}}-\mathrm{T}_{\mathrm{i}}
$$

where $\mathrm{H}_{\mathrm{f}}$ is the enthalpy of formation of the compound, $\mathrm{dT}$ is the temperature rise from the initiation temperature $T_{i}$ to the adiabatic temperature $T_{a}, C_{p}$ represents the heat capacity for the various components, and $\mathrm{H}_{\mathrm{m}}$ is the appropriate collection of melting enthalpies. The maximum temperature depends on the particular combination of reactant and compound melting events. Each melting event consumes energy and lowers the maximum temperature, while higher initiation temperatures and higher reaction heats raise the maximum temperature. Diffusional homogenization is aided by having the maximum temperature approach the compound melting temperature. Control of the maximum temperature is possible through adjustments to the processing parameters, including the initiation temperature. Generally, the most desirable situations have temperature increases of $1,500^{\circ} \mathrm{C}$. $\mathrm{TiC}$ has an adiabatic temperature of $3,210^{\circ} \mathrm{C}$, while the adiabatic temperature for $\mathrm{TiB}_{2}$ is $3,190^{\circ} \mathrm{C}$.

Several experiments have been conducted to delineate the important factors affecting CS of TiC and $\mathrm{TiB}_{2}[5,9,11-20]$. These factors include particle size, green density, degassing procedure, compact size, reaction dilution, and atmosphere effects. Several densification guidelines have emerged from previous work to include the alignment of the pressing direction with the reaction front and the occurrence of optimal densification if pressurization takes place within 1-2 s after the SHS reaction. From this basis, sequential SHS/Dynamic Compaction processing was planned.

\section{Approach}

The experimental portion of this effort was conducted at Rensselaer Polytechnic Institute in conjunction with the Rensselaer High Temperature Technology Program, which is a New-York-State-funded program whose aim, in part, is to assist small companies in technological development. This work on processing of $\mathrm{TiC}$ and $\mathrm{TiB}_{2}$ ceramics fits in with the program's 
high-temperature materials processing studies. The program is under the administration of Dr. Roger Wright, Professor of Materials Engineering at Rensselaer. The Rensselaer research team on this effort consisted of Dr. Wojciech Misiolek, Research Assistant Professor, and Dr. Theodore Schurman, Post Doctoral Research Associate, both in the Materials Engineering Department, and Mr. Nicholas Sopchak, a senior in Materials Engineering. Dr. Misiolek's field of expertise is powder processing and material flow and design. He has past experience in reactive sintering and pressure reactive sintering based on work with intermetallics and intermetallic matrix composites; Dr. Misiolek was a researcher with Professor Randall German at Rensselaer. Mr. Sopchak has worked as an undergraduate in powder metallurgy for Professor German and has experience in intermetallic thermomechanical processing. Dr. Schurman received his doctorate from Rensselaer in 1991 and has considerable experience on the Gleeble 1500 thermomechanical process simulator.

Pressure-assisted reactive sintering studies were performed on the dynamic thermomechanical process simulator Gleeble 1500 . This instrument is capable of heating specimens at $1,000^{\circ} \mathrm{C} / \mathrm{s}$ and holding steady-state equilibrium temperatures within $\pm 1^{\circ} \mathrm{C}$. Thermocouples or an infrared pyrometer provide signals for accurate feedback control of temperature. The Gleeble 1500 can operate in air or can be used with an environmental chamber. Working with the environmental chamber allows a choice of desired atmosphere or vacuum. The Gleeble 1500 mechanical system at Rensselaer is capable of applying up to 9 tons of force in tension or compression. The jaws can be programmed to move at a speed from 0.00002 to $1,000 \mathrm{~mm} / \mathrm{s}$. Strain gages and displacement transducers provide feedback, which allows accurate execution and repeatability of the simulation program. Important process variables, such as force, stroke, strain, and strain rate are monitored during the simulation. The Gleeble 1500 may be controlled either by computer or manual control. It is also possible to operate the apparatus with a combination of computer and manual control to provide maximum versatility in the simulation experiment. The unit may be operated in load control or stroke control mode. In load control mode, the force is measured by load cells and kept constant while stroke is adjusted to maintain the desired force. Similarly, in stroke control, the force is adjusted to achieve the desired stroke change. Ten volts (AC) are applied across the sample, and current is adjusted causing the sample to heat by resistance heating. Roughly $25 \%$ of the heat is lost from the sample by radiation and by lengthwise conduction through the water-cooled copper jaws. 
When operating the Gleeble in temperature control mode, temperature is monitored and power is adjusted to match the programmed schedule. There is a significant problem when this mode is used for studying the exothermic reactions. Because of the exothermic reaction, the sample's temperature rises and the instrument attempts to compensate for the temperature rise by reducing the power being delivered to maintain a constant heating rate. The consequence is that the exothermic reaction is masked. An adjustment was made during the effort by Duffers Scientific Associates of Poestenkill, NY, the manufacturer of the Gleeble, to allow the instrument to be run in power control mode. In this mode, a constant power level is supplied to the sample and thus the exothermic reaction does not result in a reduction of the electrical current being delivered to the sample. A second modification was made to the mechanical system, allowing the vacuum gauge to trigger application of the applied force. Since vast outgassing would take place during the exothermic reaction, timing for applying force may be based on when the amount of outgassing causes the vacuum to degrade above a given preset level. The vacuum gage is employed to trigger the application of force when vacuum starts to deteriorate because of immense outgassing.

The initial approach was to start by fabricating $1.25-\mathrm{cm}$-diameter $\times 2.5$-cm-thick samples of $\mathrm{TiB}_{2}$ and $\mathrm{TiC}$. The reason for this was to conserve material and to establish the proper process parameters for scaleup to the 10-cm-diameter samples. A special die for fabricating cylindrical samples $1.25 \mathrm{~cm}$ in diameter and $2.5 \mathrm{~cm}$ thick was designed and built for this study. The die was made from a graphite tube, $1.25-\mathrm{cm}$ inside diameter (ID), $1.78-\mathrm{cm}$ outside diameter (OD), and $8.8-\mathrm{cm}$ length. G540 grade graphite was chosen for the die material because of its properties at room and elevated temperatures (compressive strength of $98 \mathrm{MPa}$ [14 ksi] at room temperature). With no reinforcement around the graphite die, a maximum force of roughly $70 \mathrm{MPa}(10 \mathrm{ksi})$ may be applied at room temperature and a maximum force of $6,700 \mathrm{~N}(1,500 \mathrm{lbf})$ may be applied at $1,500^{\circ} \mathrm{C}$. The source for the graphite was Southern Graphite USA, Inc., in East Windsor, CT. A schematic of the die design is shown in Figure 1. Powders of $\mathrm{TiC}$ and $\mathrm{TiB}_{2}$ were to be contained in the graphite tube, and the graphite was to be supported by two split alumina tubes that were pressed against the graphite tube. The two ceramic tubes measured $1.78-\mathrm{cm} \mathrm{ID} \times 2.5-\mathrm{cm} \mathrm{OD}$ and $2.5-\mathrm{cm} \mathrm{ID} \times 3.1-\mathrm{cm} \mathrm{OD}$, respectively, and both tubes were $7.5 \mathrm{~cm}$ in length. The alumina and graphite tubes were contained 


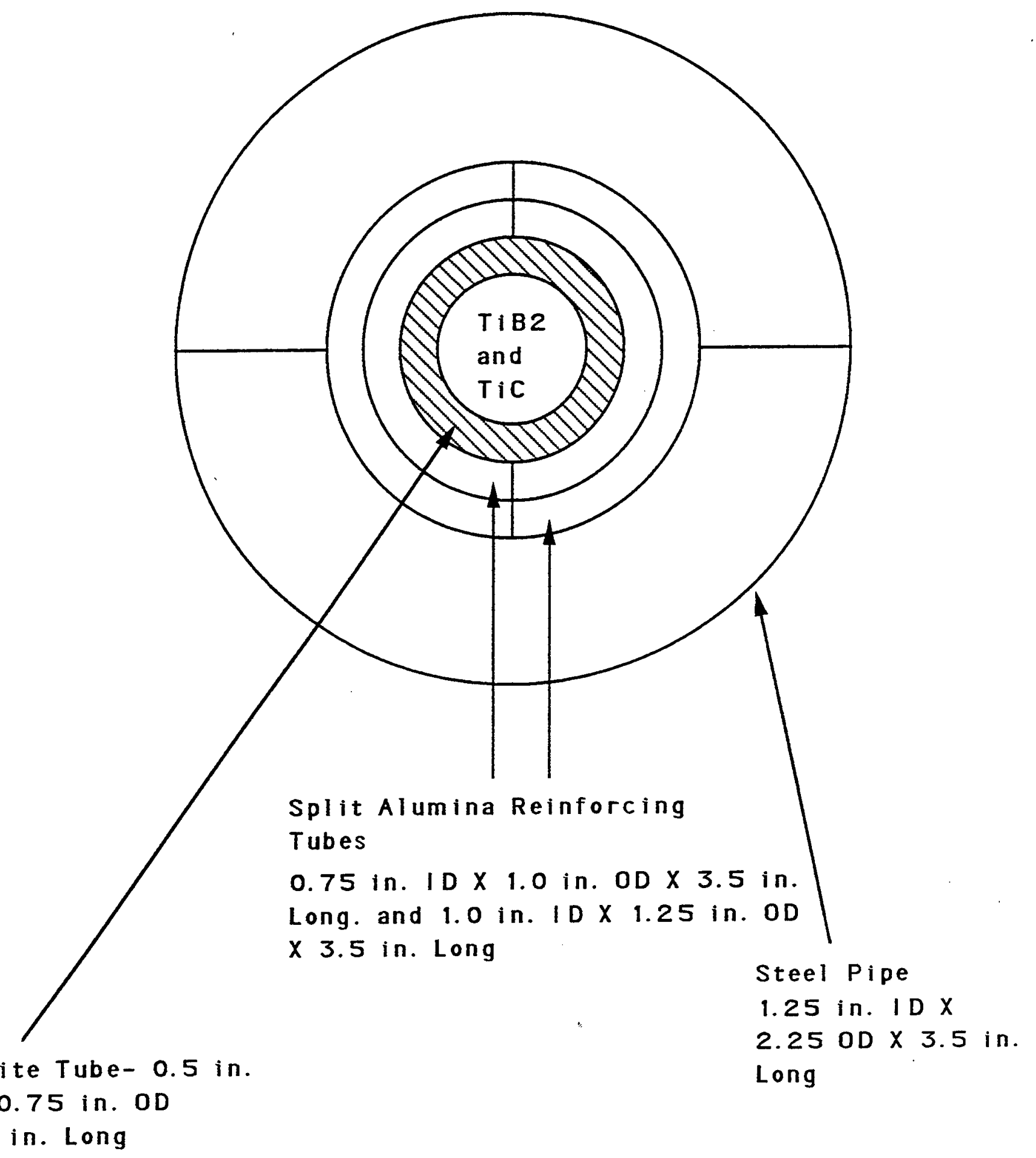

Figure 1. Die Design, Axial View. 
by a steel pipe, which was also split down its long axis and fixtured around the other tubes using hose clamps. The entire die assembly was fitted between the jaws of the Gleeble and within the vacuum chamber of the system. The anvils were made from tungsten carbide (WC), which contains roughly $6 \mathrm{wt} . \%$ cobalt $(\mathrm{Co})$. The material has its service temperature limited by creep at about $1,100^{\circ} \mathrm{C}$. Graphite end plugs were placed between anvils and powder compact to prevent sintering of the densified sample to the WC-Co anvils. When the Gleeble operated in compression, one of its jaws was fixed while the other jaw moved to apply the loading on the sample. Figure 2 shows a side view of the die assembly and clearly indicates the position of the anvils against the graphite plugs. The initial WC-Co anvils measured $1.26 \mathrm{~cm}$ in diameter to ensure a good fit within the graphite tube. Grafoil (thin sheets of graphite material) was also obtained to be placed on the inside of the graphite tube to prevent sticking of either the $\mathrm{TiC}$ or $\mathrm{TiB}_{2}$ against the walls of the tube.

\section{Reactive Sintering/Dynamic Compaction}

4.1 Material Preparation. Elemental $\mathrm{Ti}$ and graphite or $\mathrm{Ti}$ and $\mathrm{B}$ powders were weighed in proportion to form $\mathrm{TiC}$ and $\mathrm{TiB}_{2}$, respectively. The powders purchased for these experiments are shown in Table 1. Their scanning electron micrographs (SEMs) showing particle morphology are presented in Figures 3, 4, 5, 6, and 7. The TiC system was evaluated first for reactive sintering and dynamic compaction studies. It was decided to study the TiC system first and then apply the gained knowledge and experience to the $\mathrm{TiB}_{2}$ system.

As shown in Table 1, the Ti powder was received from Micron Metals and the graphite powder used was the Micro 250 synthetic graphite from Asbury Graphite Mills. The Ti powder was reported by the vendor as being -325 mesh, but particle size analysis showed the powder to be an average of $44 \mu \mathrm{m}$ in diameter. The powder was sieved through a $325-$ mesh screen to obtain actual -325 mesh powder. The mean particle sizes are shown in Table 2. The particle size distributions are plotted in Figures 8-12. 


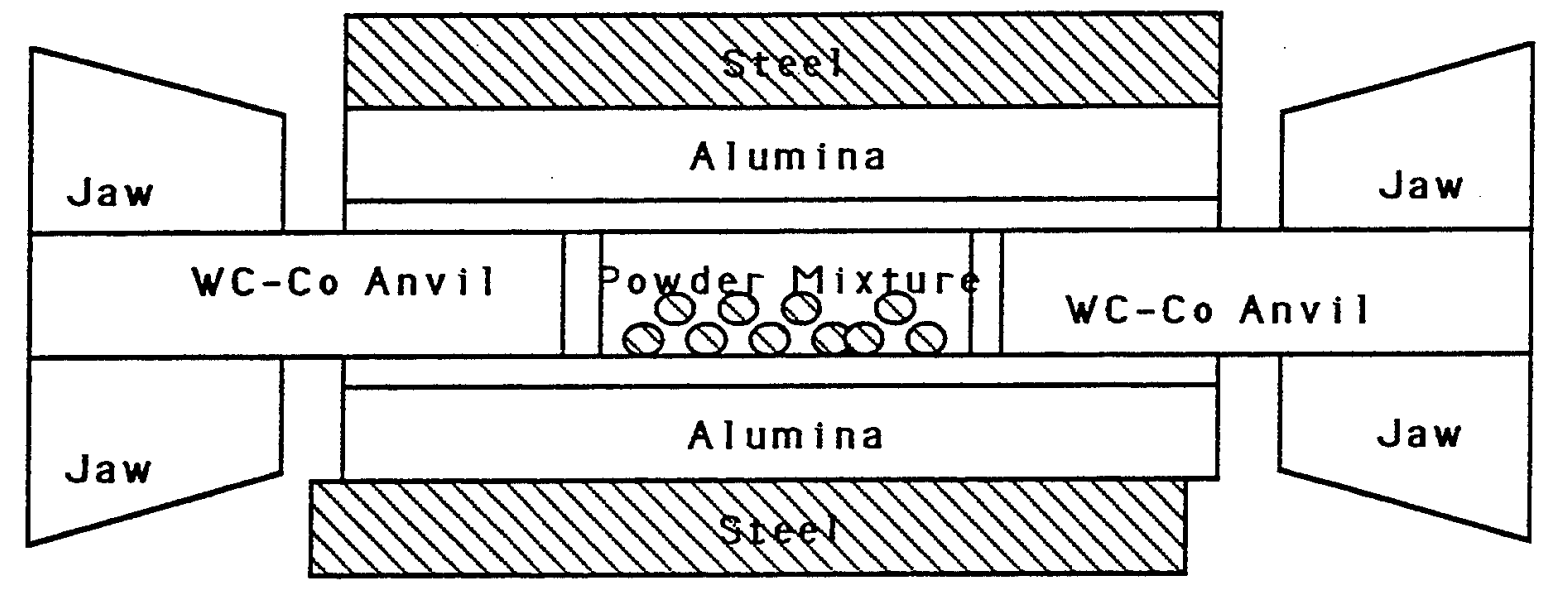

Figure 2. Die Assembly, Side View.

Table 1. Listing of Powders Employed in Study

\begin{tabular}{||l|l|l|c|c|c||}
\hline Powder Name & \multicolumn{1}{|c|}{ Vendor } & Designation & Size & $\begin{array}{c}\text { Cost } \\
\text { (per/lb) }\end{array}$ & $\begin{array}{c}\text { Quantity } \\
\text { (in house) }\end{array}$ \\
\hline $\begin{array}{l}\text { Boron } \\
\text { (amorphous) }\end{array}$ & Hermann Starck & Grade I lot 1/91 & $0.84 \mu \mathrm{m}$ & $\$ 135.00$ & $0.5 \mathrm{~kg}$ \\
\hline $\begin{array}{l}\text { Boron } \\
\text { (crystalline) }\end{array}$ & Hermann Starck & Lot 288/91 & $-325 \mathrm{mesh}$ & $\$ 370.00$ & $0.5 \mathrm{~kg}$ \\
\hline $\begin{array}{l}\text { Graphite } \\
\text { (natural) }\end{array}$ & $\begin{array}{l}\text { Asbury Graphite } \\
\text { Mills }\end{array}$ & Micro 850 & $4.22 \mu \mathrm{m}$ & $\$ 6.40$ & $10 \mathrm{lb}$ \\
\hline $\begin{array}{l}\text { Graphite } \\
\text { (synthetic) }\end{array}$ & $\begin{array}{l}\text { Asbury Graphite } \\
\text { Mills }\end{array}$ & Micro 250 & $4.27 \mu \mathrm{m}$ & $\$ 6.20$ & $10 \mathrm{lb}$ \\
\hline Nickel & Novamet & 123 & $12.81 \mu \mathrm{m}$ & $\$ 9.24$ & $11 \mathrm{lb}$ \\
\hline Nickel & Novamet & 4 SP & $11.81 \mu \mathrm{m}$ & $\$ 9.34$ & $11 \mathrm{lb}$ \\
\hline Ti & Micron Metals & Ti-020 & $-325 \mathrm{mesh}^{\mathrm{a}}$ & $\$ 28.00$ & $20 \mathrm{lb}$ \\
\hline
\end{tabular}

${ }^{a}$ Size given by vendor. 

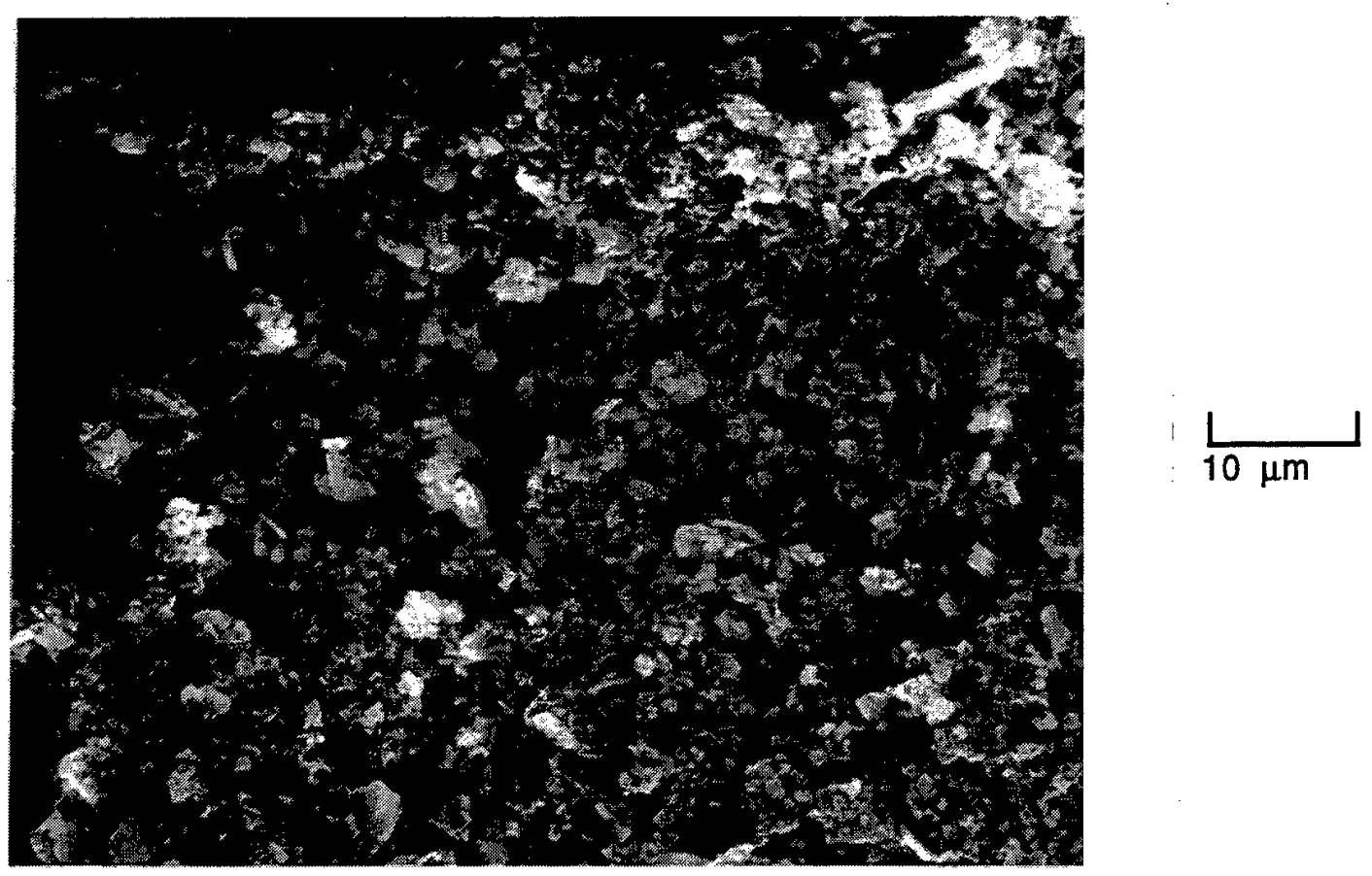

Figure 3. SEM of Amorphous Boron Powder.
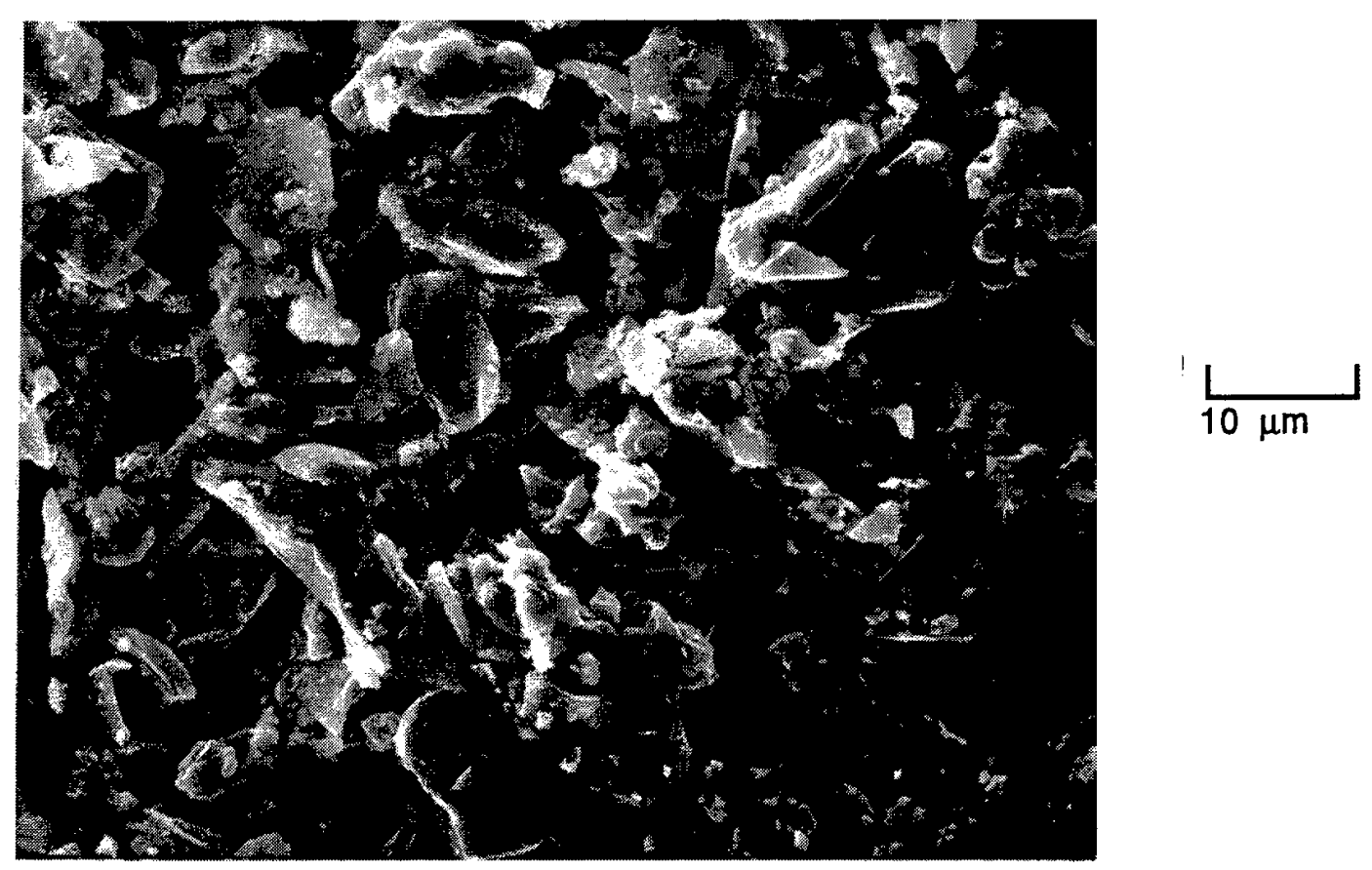

Figure 4. SEM of Crystalline Boron Powder. 

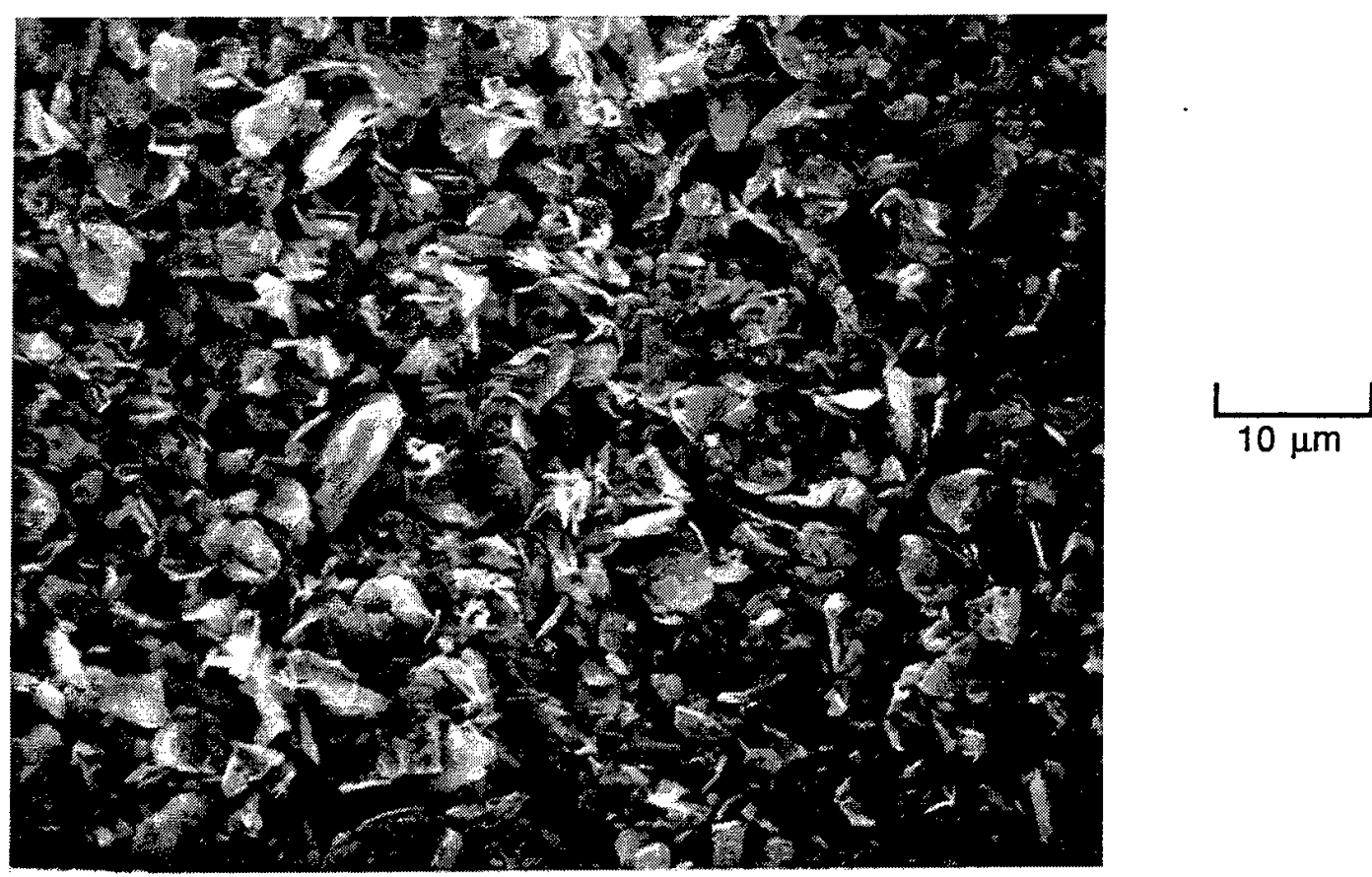

Figure 5. SEM of Natural Graphite Powder.

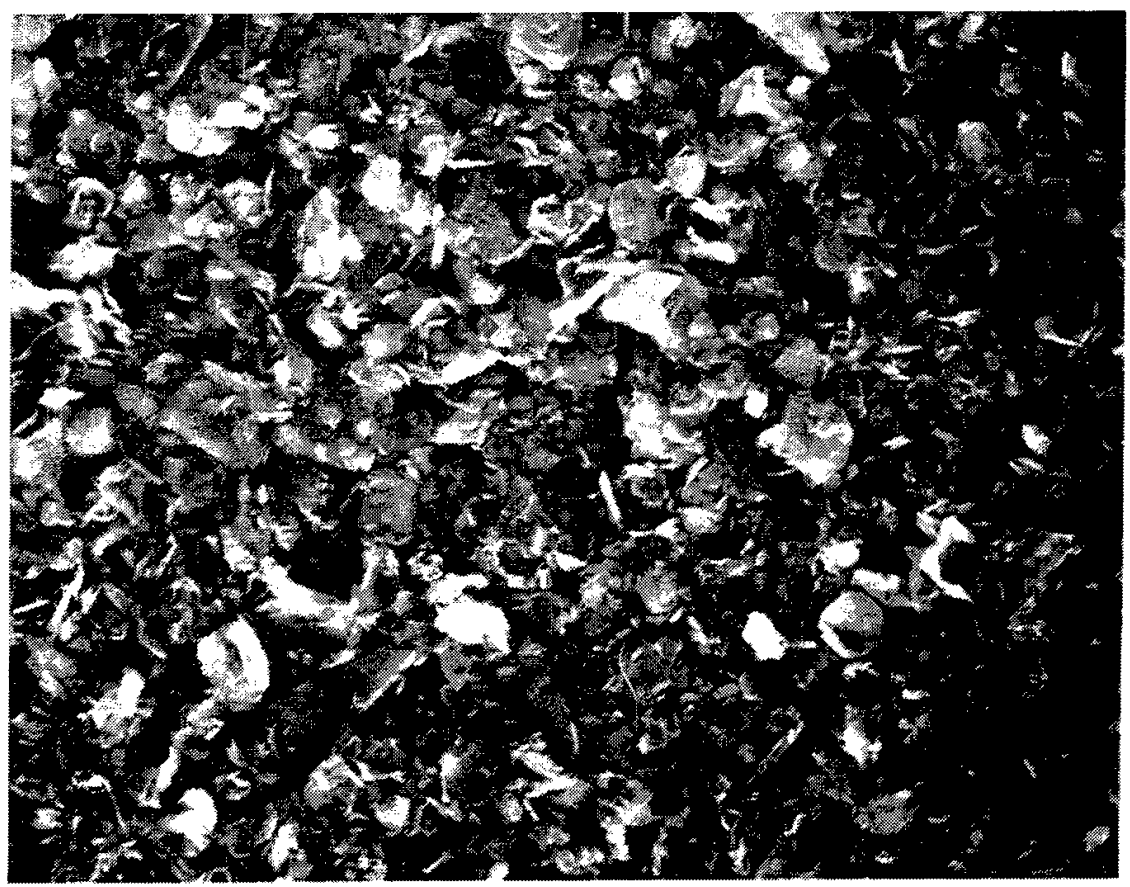

$10 \mu \mathrm{m}$

Figure 6. SEM of Synthetic Graphite Powder. 


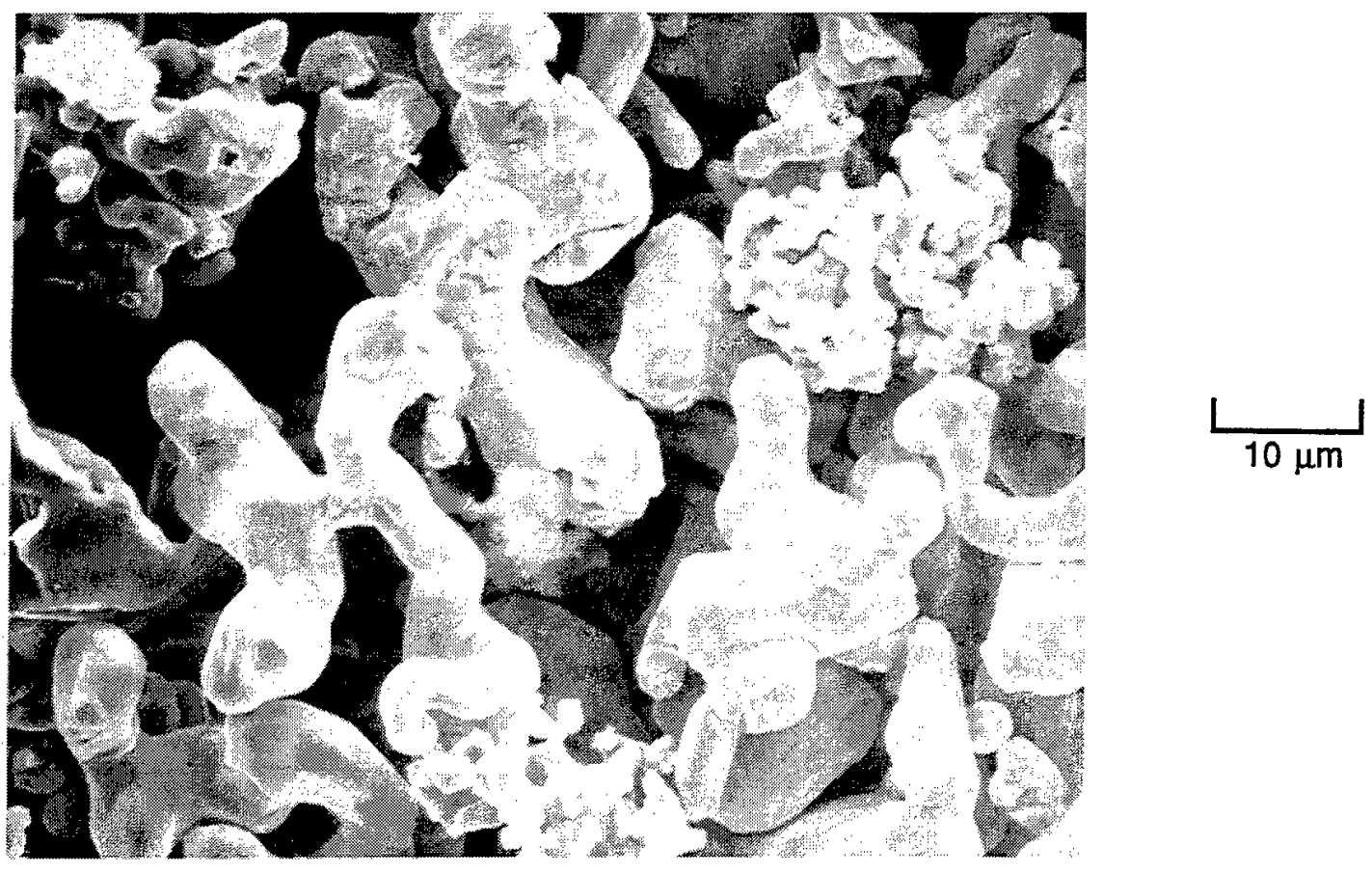

Figure 7. SEM of Titanium Powder.

Table 2. Mean Particle Sizes of Powder

\begin{tabular}{|c|c||}
\hline $\begin{array}{c}\text { Powder } \\
\text { (mean) }\end{array}$ & $\begin{array}{c}\text { Particle Size } \\
(\mu \mathrm{m})\end{array}$ \\
\hline \hline Crystalline B & 18.0 \\
\hline Amorphous B & 2.10 \\
\hline Graphite 250 (Synthetic) & 6.17 \\
\hline Graphite 850 (Natural) & 8.74 \\
\hline Ti & 34 (after sieving) \\
\hline
\end{tabular}

Based on the theoretical density of the ceramic product and a desired final dimension of $2.5-\mathrm{cm}$ long $\times 1.25-\mathrm{cm}$-diameter, $15.8 \mathrm{~g}$ of $\mathrm{Ti}$ and graphite powder were added to the graphite die. Knowing the starting amount of material, it was possible to monitor densification during heating and reactive sintering by following stroke displacement. After weighing and combining, the powders 


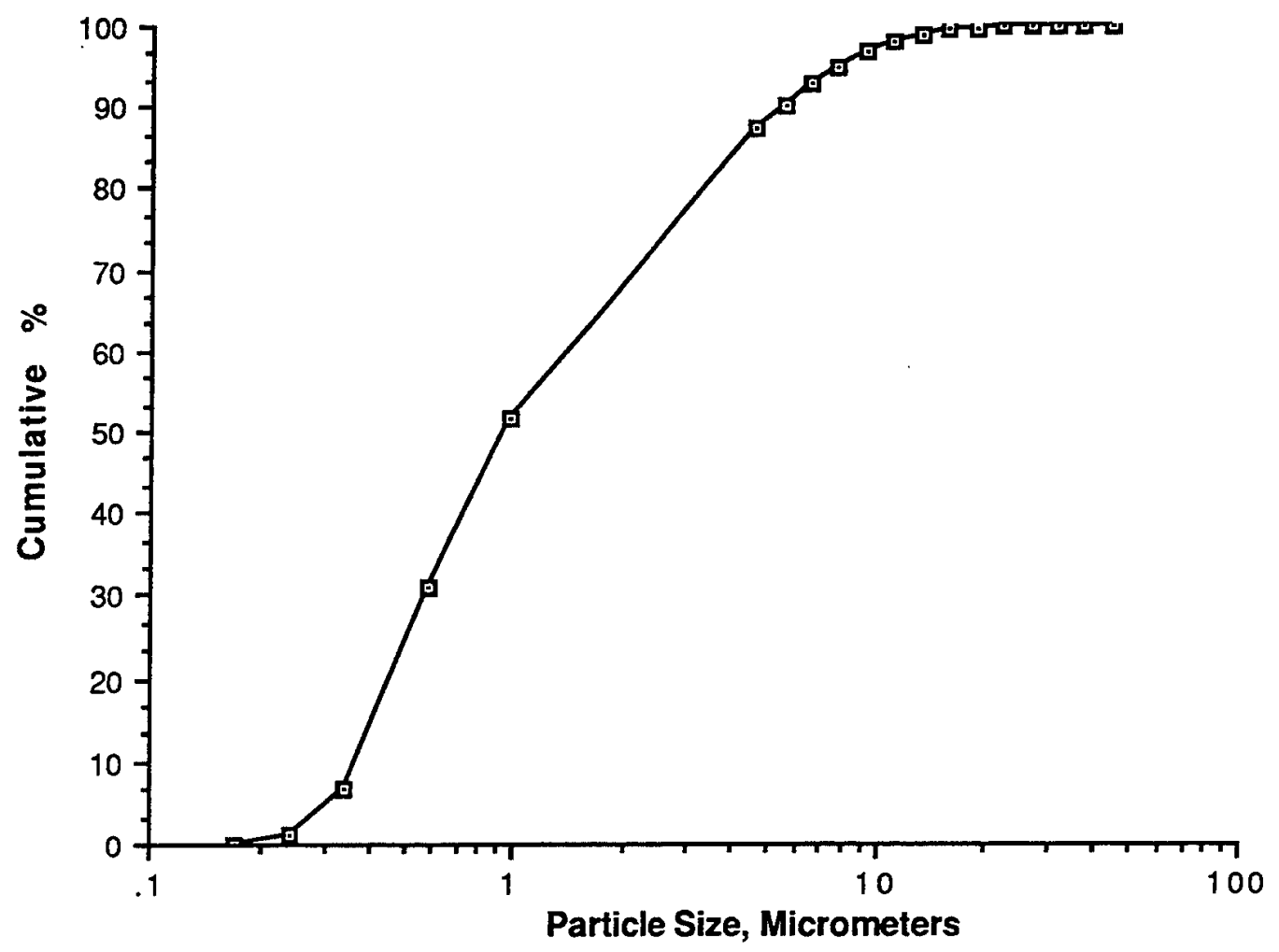

Figure 8. Particle Size Distribution for Amorphous Boron.

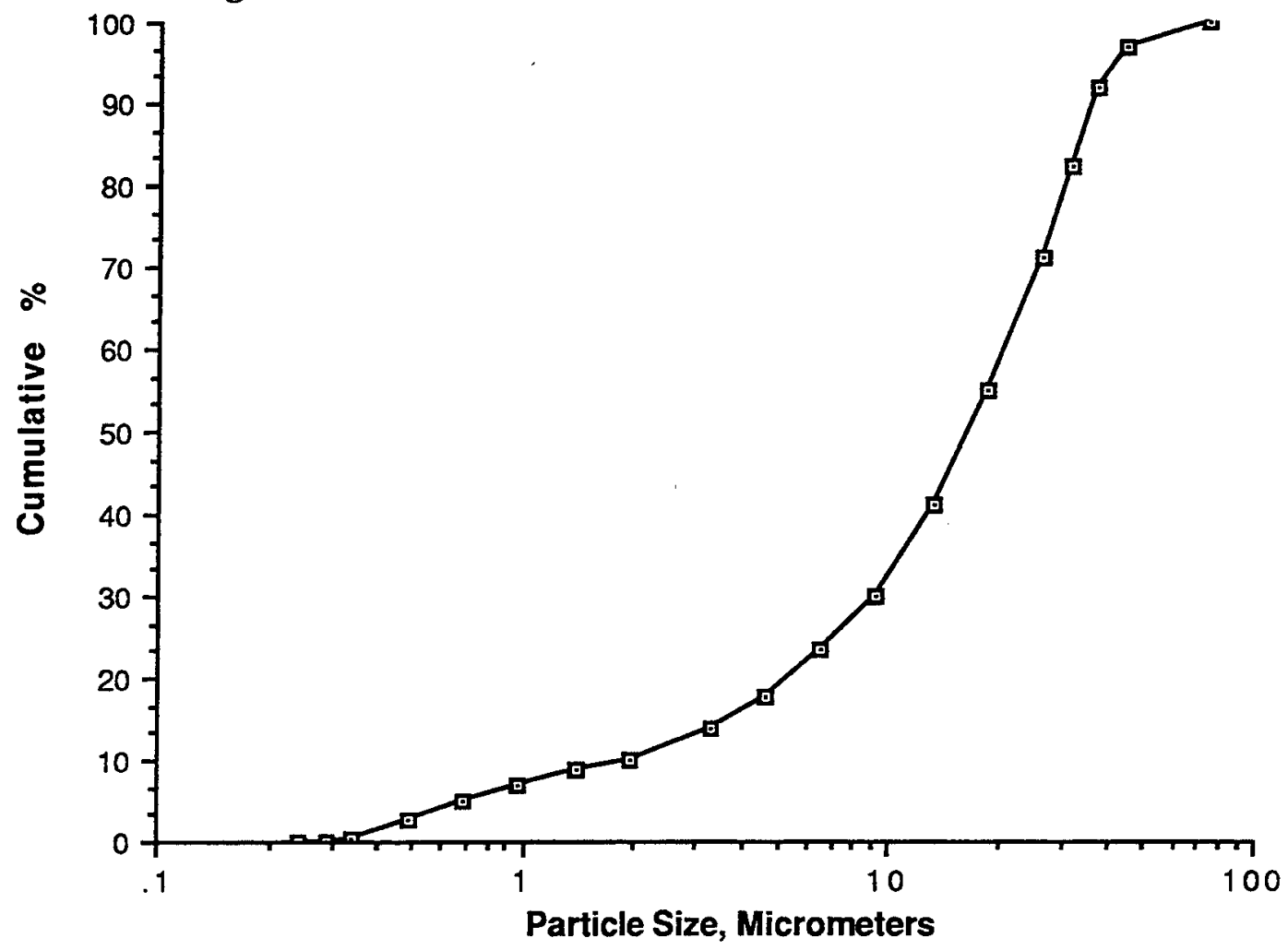

Figure 9. Particle Size Distribution for Crystalline Boron. 


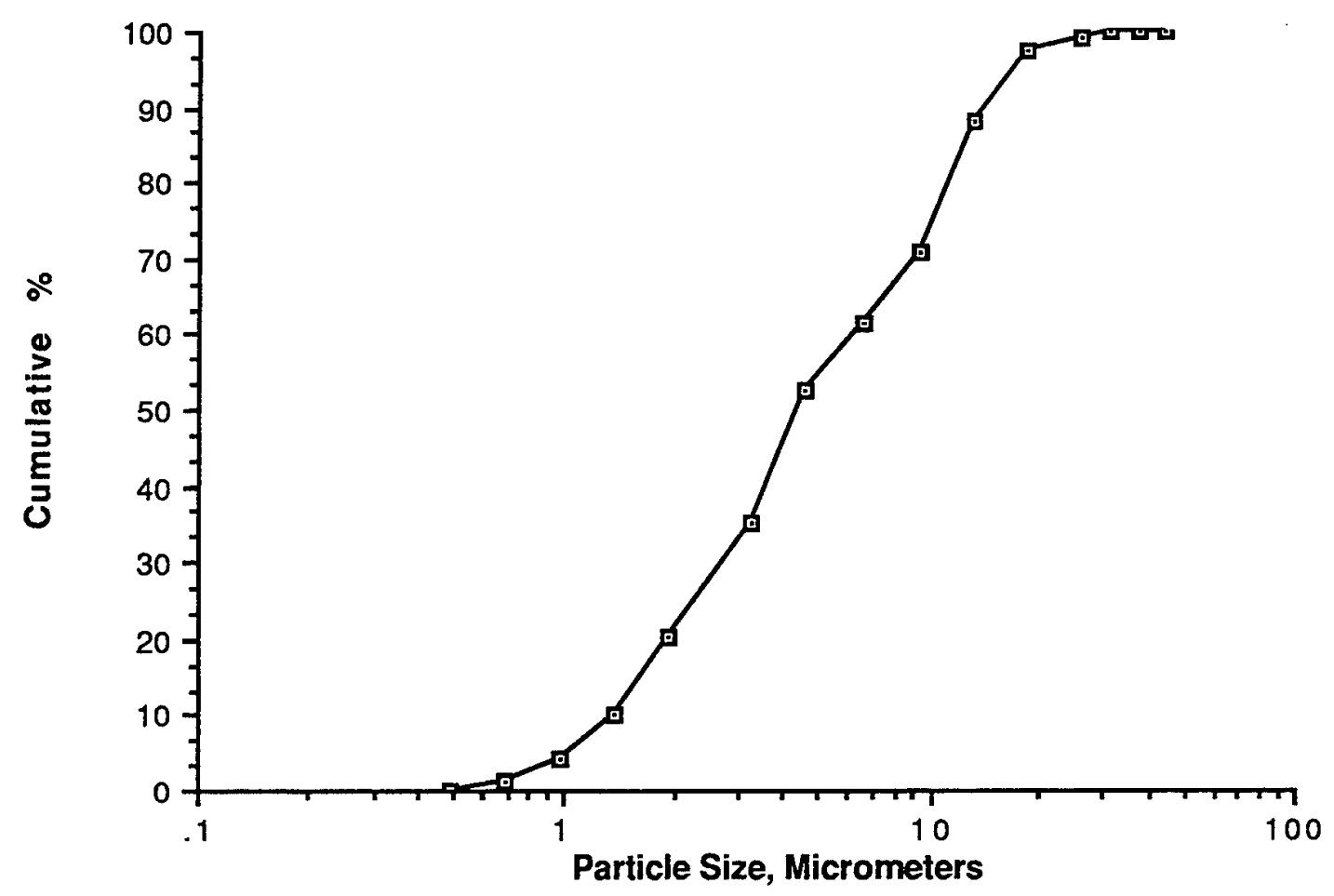

Figure 10. Particle Size Distribution for Synthetic Graphite.

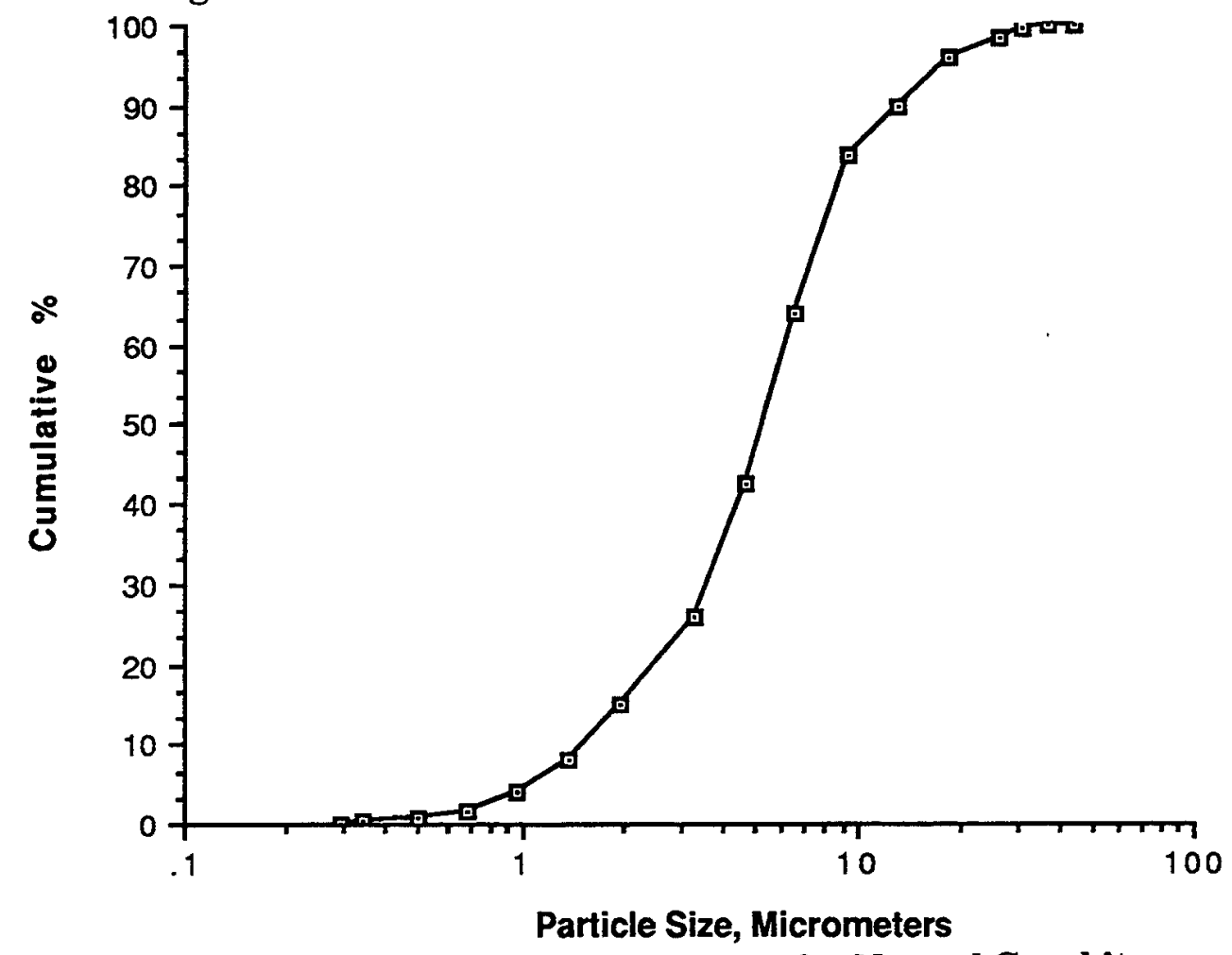

Figure 11. Particle Size Distribution for Natural Graphite. 


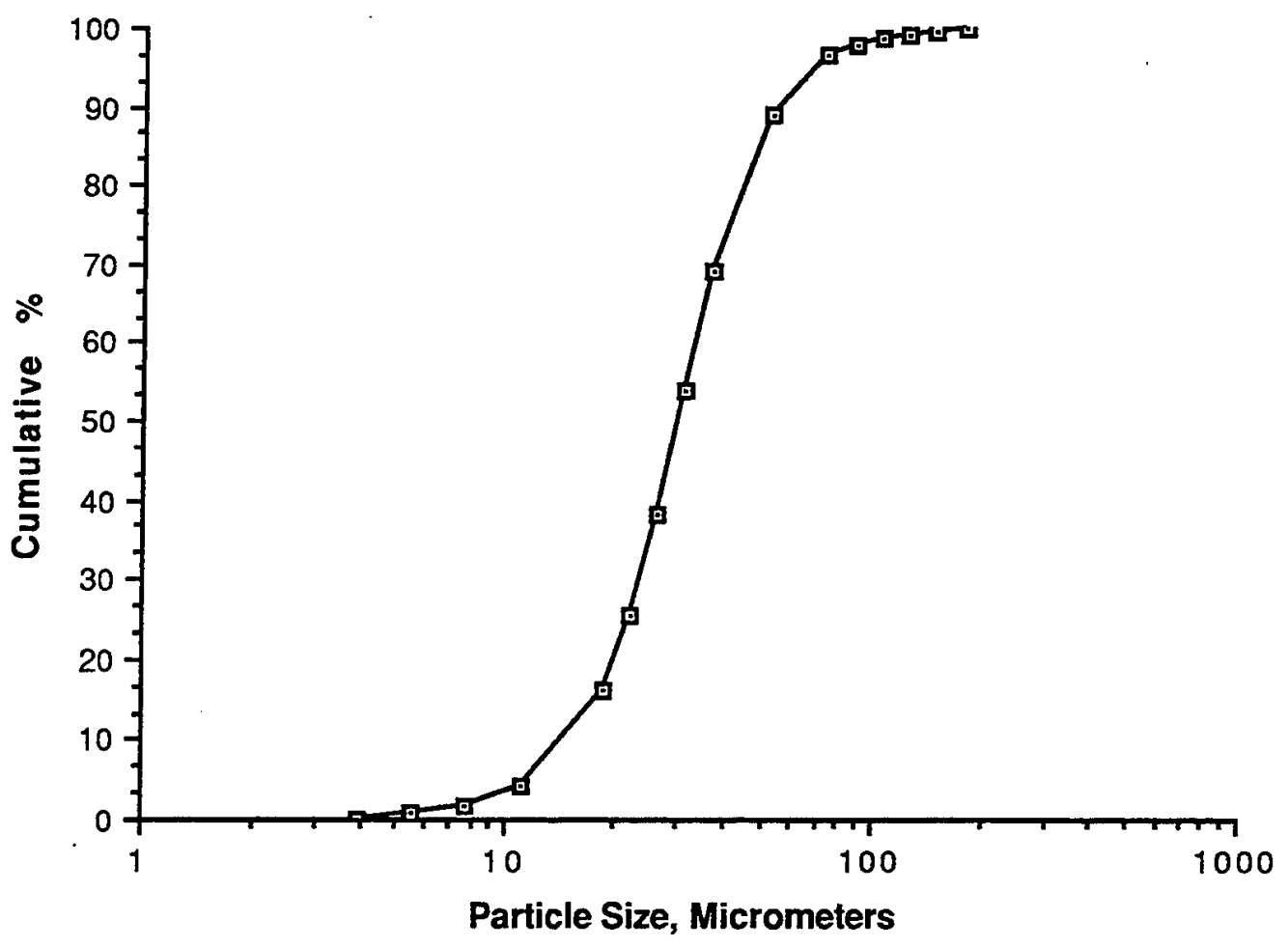

Figure 12. Particle Size Distribution for Titanium.

were mixed together in a Turbula mixer for $30 \mathrm{~min}$ and then the powder mixture was loaded into the graphite die and pressed on a hydraulic press using double-action compaction to form a $60 \%$ dense green sample. Roughly $35 \mathrm{MPa}$ ( $5 \mathrm{ksi}$ ) of pressure was employed for greening the sample. The loaded die was moved from the hydraulic press to the Gleeble 1500 testing machine. No Ni powder was added to the $\mathrm{TiC}$ for the first set of testing.

4.2 Experimental Procedure. Both sample material and the die were resistance heated by the flowing current. Heating rates were limited by cracking of the die because of thermal expansion mismatch. High heating rates can lead to die cracking because of the thermal expansion difference between the sample and the die material. (The die may also crack during rapid cooling after completed densification because of thermal shock.) 
The Gleeble 1500 could not be run initially due to the fact that the system was temperature controlled through the reading from the chromel-alumel thermocouple. The thermocouple would melt after the $\mathrm{Ti}$ and graphite mixture went exothermic and the electrical system triggering the hydraulic load system would be shut down. Duffers Scientific Associates installed a power control module that allowed the machine to be run in power control mode and did not rely on feedback from the thermocouple.

Once the module was added, an experiment was performed using the roughing pump and diffusion pump to draw high vacuum within the chamber containing the die assembly and sample. A chromel-alumel thermocouple was attached to the graphite tube using a cement-based sealant. Degassing of the powders was performed at $600^{\circ} \mathrm{C}$ for $30 \mathrm{~min}$ and then the temperature was increased at a rate of $10^{\circ} \mathrm{C} / \mathrm{s}$. The large exotherm associated with reactive sintering was observed between 800 and $1,100^{\circ} \mathrm{C}$ during rapid heating. Outgassing from the reaction would crack the graphite die. The actual initiation temperature varied and sometimes would not be reached, therefore preventing CS. While operating in power control mode, a tungsten-rhenium thermocouple was embedded in the powders and the sample was heated to allow the sample to reach the initiation temperature for CS. The thermocouple would eventually fail, which indicated that the exotherm had to have exceeded the $2,400^{\circ} \mathrm{C}$ melting temperature of the thermocouple. The WC anvils melted during this experiment, which also indicated that a significant amount of heat was being lost longitudinally through the anvils.

Experiments were continued using the graphite die surrounded by a split steel die to allow application of high pressures. Outgassing from the reaction shattered the graphite die when it was used unsupported. A thermocouple was welded to the steel, and the steel was in direct contact with the graphite tube. Force was applied using manual control after onset of CS. Densities less than $80 \%$ were being obtained with this approach, as force was probably being applied too late. It was then that the vacuum gauge was added for triggering the hydraulic system of the Gleeble. Timing of the compaction was associated with a given amount of outgassing. A value such as 10 or $50 \times$ $10^{-3}$ Torr would be preset so that when this value was exceeded as the chamber started to lose 
vacuum, load would be applied to achieve dynamic compaction. With this approach, it still was not possible to achieve densities greater than $80 \%$ of theoretical. The maximum temperature recorded on the outside of the graphite tube after the exothermic reaction was $1,400^{\circ} \mathrm{C}$, which indicated that most of the heat loss was occurring longitudinally and not radially. Heat loss from the compact was such that, when load was applied, not enough of the latent heat from the CS reaction was remaining in the sample to keep the compact at a sufficient temperature for dynamic compaction to achieve high densities.

A significant heat loss was occurring due to radiation, direct conduction, and electronic conduction. Radiation loss is estimated to be up to $25 \%$ of the entire heat lost. Loss due to conduction longitudinally is significant and accounts for the bulk of the remaining heat loss. Samples processed by this method must be electrically conductive for resistance heating to occur, and consequently, unwanted thermal conductivity in the form of heat loss to the jaws of the testing machine also takes place. This described heat loss can lower the temperature of the sample in a very short time after the reaction such that further densification is greatly limited. With the resistance heating approach, the amount of heat loss longitudinally may be reduced by employing materials of varying electrical resistances between the anvil and sample. The sample will take longer to heat, but loss of heat through conduction will also be reduced. Heat loss will still occur, and it is uncertain if adiabatic conditions will be approximated enough for there to be enough heat remaining in the sample to obtain high densities at the time the load is applied.

It was observed in these studies that when the pressure was greater than $35 \mathrm{MPa}$ during heating to the initiation temperature, the sample would not self-propagate, which is consistent with the literature findings that increasing the pressure of the compacted powder mixture prior to ignition can significantly retard the combustion. Most likely, developed enthalpy is dissipated quickly and the critical enthalpy for combustion is not reached.

The greatest densities achieved using reactive sintering and dynamic compaction were $82 \%$. Further attempts at processing $\mathrm{TiC}$ using compaction following reactive sintering were suspended 
based on success at getting $\mathrm{TiC}$ to form at low temperature without observation of the large exotherm. Early in the effort, tests were conducted heating the powder mixture while applying force, and though the large exotherm typically associated with CS was not observed, the vacuum level would decrease within the chamber but vacuum would not be lost completely. This change in vacuum level would occur from 700 to $900^{\circ} \mathrm{C}$, as measured on the graphite die. Associated with the decrease in vacuum was an associated stroke change that would eventually cease. Stopping the test at this point generated a compact that was roughly $73 \%$ dense, and $\mathrm{x}$-ray analysis confirmed that the $\mathrm{Ti}$ and graphite had reacted to form $\mathrm{TiC}$.

\section{Current-Induced SHS}

5.1 1.25-cm-Diameter Evaluation Studies. The "steady" current-induced SHS technique was developed in this study. During degassing under compaction stress ranging from 17.5 to $35 \mathrm{MPa}$, some densification took place as the sample heated. Stroke change leveled off at $600^{\circ} \mathrm{C}$, and following degassing, densification would resume again at $700^{\circ} \mathrm{C}$. Stroke change would be observed for approximately $15 \mathrm{~min}$ after which time densification would cease. X-ray diffraction confirmed $100 \%$ transformation to TiC. Figure 13 shows a typical plot of stroke change as a function of temperature and pressure during current-induced SHS. This plot is from the 10-cm-diameter sample, but it is also representative of the 1.25 -cm-diameter samples. The time for transformation of the 10-cm-diameter sample to $\mathrm{TiC}$ was longer than for the $1.25-\mathrm{cm}$-diameter samples because of the larger mass and caution employed to keep the samples from self-propagating. Further testing helped to understand the mechanism for the reaction.

The current-induced process transforms the elemental powders to $\mathrm{TiC}$ in a controlled manner, maintaining low overall temperatures and without the onset of the violent exothermic reaction. Both $\mathrm{TiC}$ and $\mathrm{TiB}_{2}$ have been formed using this process without the gross temperature of the containing graphite die exceeding $800^{\circ} \mathrm{C}$. To reiterate, the process works as follows: electrical current is passed through the electrically conductive elemental powders. Very high current densities are developed locally at particle interfaces. Heating results from the electrical resistance of the particle 


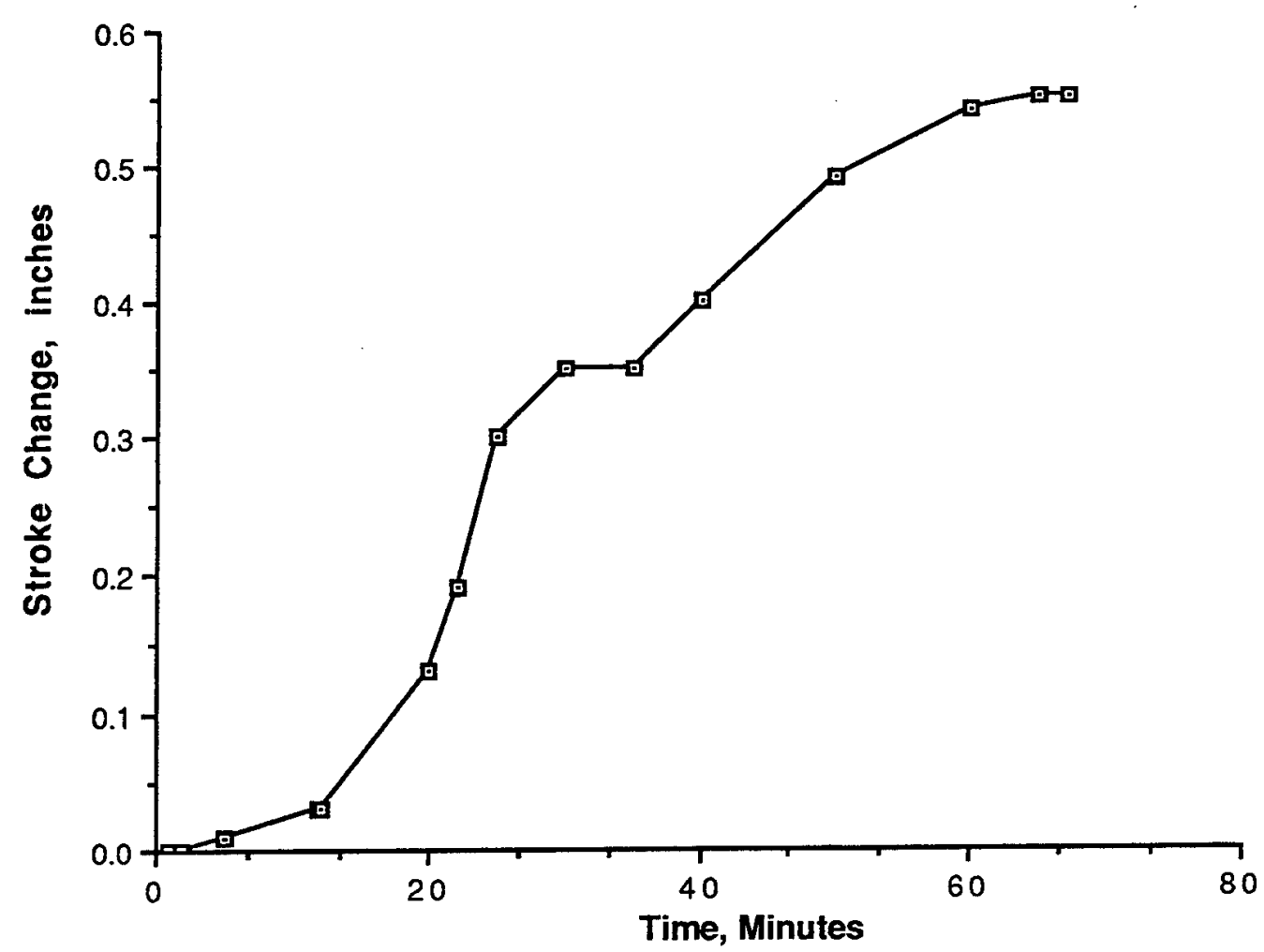

Figure 13. 10-cm TiC Transformation Plot.

interfaces. This heat is sufficient to cause transformation locally. However, the reaction stagnates and does not self-propagate since heat is conducted/radiated from the system faster than neighboring elements could reach the critical temperature for CS. As current continues to flow into the compact, the electrical resistance of the regions that have reacted decreases while untransformed regions continue to react and stagnate until eventually all of the elemental powders have been transformed.

Transformation occurs faster at $800^{\circ} \mathrm{C}$ than at $700^{\circ} \mathrm{C}$. Increasing the current to raise the temperature can cause the remaining unreacted powders to go exothermic. (Recall-the current-induced technique employed an unsupported graphite die, so if a large volume of the powder was allowed to self-propagate, degassing would have shattered the die.) As pressure is increased from 17.5 MPa to $35 \mathrm{MPa}$, the time for complete transformation is reduced. The density of samples following this reaction is consistently $73 \%$ of theoretical. The presence of 3 wt.- $\%$ Ni does not change the transformation process. 
The TiC material was densified to $95-97 \%$ by electrically heating the sample after synthesis using the steady current-induced SHS technique. With 3 wt.- $\% \mathrm{Ni}$ added to TiC and with $35 \mathrm{MPa}$ pressure, densification occurs at $1,300^{\circ} \mathrm{C}$. The maximum sintering temperature examined for $\mathrm{TiC}$ with $3 \mathrm{wt} .-\% \mathrm{Ni}$ was $1,500^{\circ} \mathrm{C}$, and a $97 \%$ density was obtained at $56 \mathrm{MPa}$ (8 ksi). The time at temperature was approximately $15 \mathrm{~min}$. Using current to heat the compact appears to significantly reduce the time needed for densification. Microhardness testing could not be performed without cracking the Ni-based matrix. The Vickers hardness at 500-gf load was approximately $19 \mathrm{GPa}$, and the Ni-based matrix was cracked from the indentation.

$\mathrm{TiC}$ without Ni would transform at $700-800^{\circ} \mathrm{C}$ but would not densify at the combination of $1,500^{\circ} \mathrm{C}$ and $56 \mathrm{MPa}$. The material would creep at $1,700^{\circ} \mathrm{C}$ and $35 \mathrm{MPa}$, but the density rate would eventually stagnate. As the density increased, higher temperatures and pressures were required to further densify the compact.

$\mathrm{TiB}_{2}$ showed the same transformation temperature as $\mathrm{TiC}$ with the current-induced process at $800^{\circ} \mathrm{C}$ using $35 \mathrm{MPa}$ of pressure but did not demonstrate the same densification as $\mathrm{TiC}$ at $1,500^{\circ} \mathrm{C}$ and $56 \mathrm{MPa}$. The Gleeble begins to overheat as more current is brought to the compact to raise its temperature above $1,500^{\circ} \mathrm{C}$. Because of this overheating, we could not explore temperatures at which densification would occur for $\mathrm{TiB}_{2}$. Limitation of the present apparatus prevented additional high-temperature processing for the $\mathrm{TiB}_{2}$ system.

Figures 14-17 show the $\mathrm{x}$-ray diffraction patterns for $\mathrm{TiC}$ and $\mathrm{TiB}_{2}$. Except for Figure 17, the analyses are for 1.25-cm-diameter samples. Analysis shown in Figure 14 is from a sample that was identified as $\mathrm{A} 5$ and was the first in which the current-induced transformation was noted. X-ray analysis of the sample verified that $\mathrm{TiC}$ had been produced from the elemental powders. Sample A5 was $72 \%$ dense after transformation. Figure 15 shows the $\mathrm{x}$-ray diffraction pattern for a sample that was brought to $1,500^{\circ} \mathrm{C}$ following transformation and sintered to $96 \%$ density. This sample contained $3 \mathrm{wt} . \% \mathrm{Ni}$. The $\mathrm{TiB}_{2}$ sample that was transformed to approximately $73 \%$ density by the current-induced transformation process was analyzed and confirmed to be $\mathrm{TiB}_{2}$ by $\mathrm{x}$-ray diffraction. 


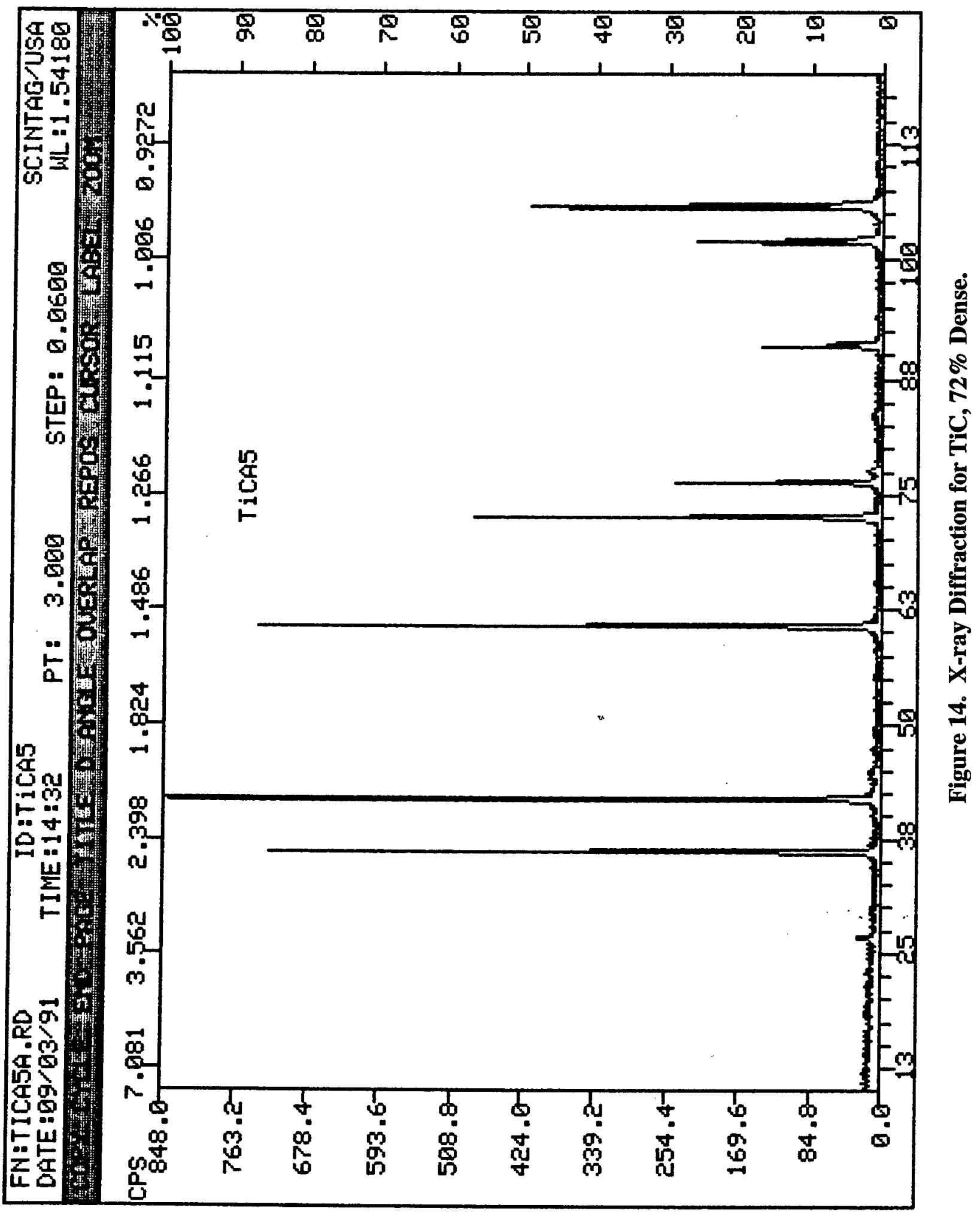




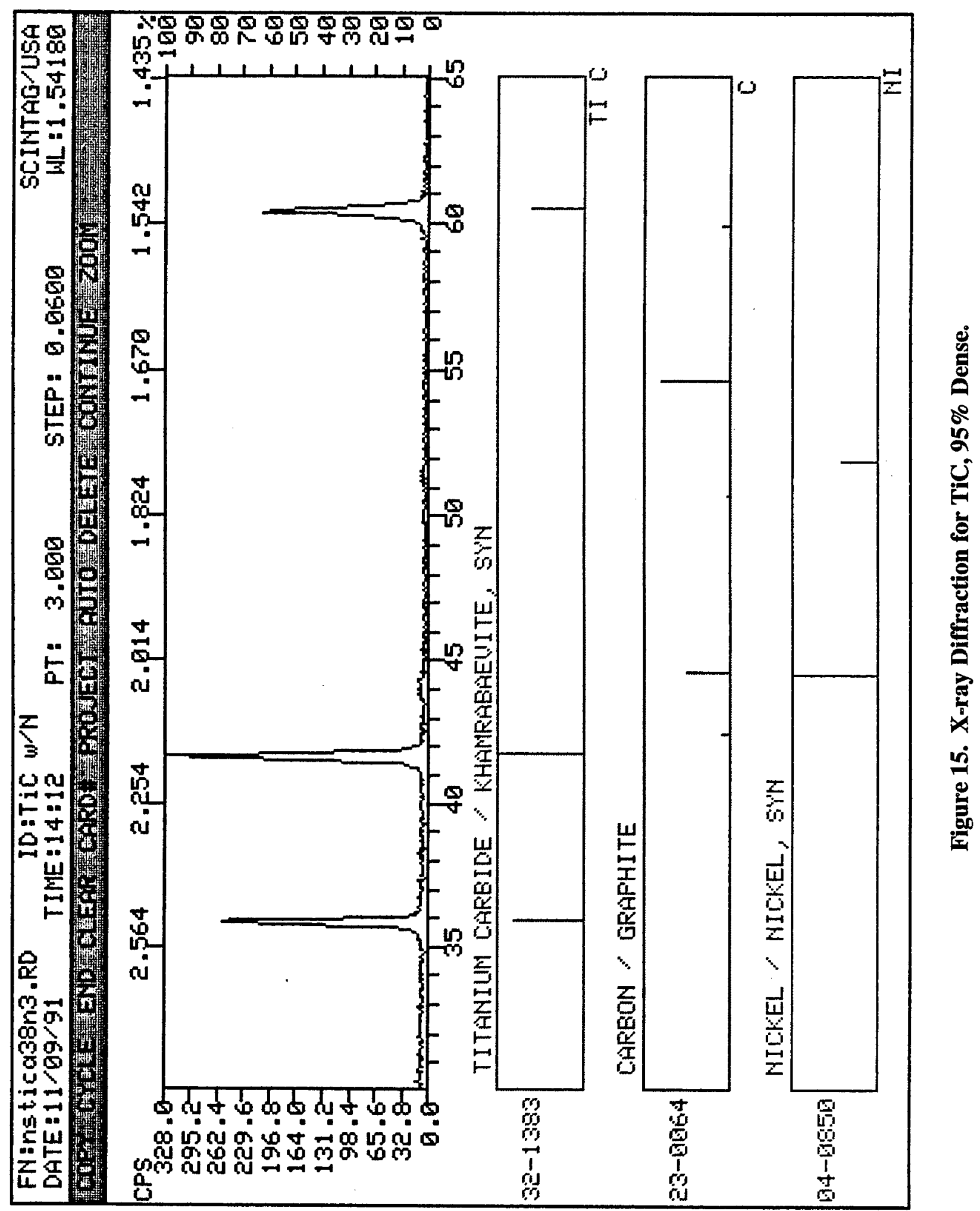




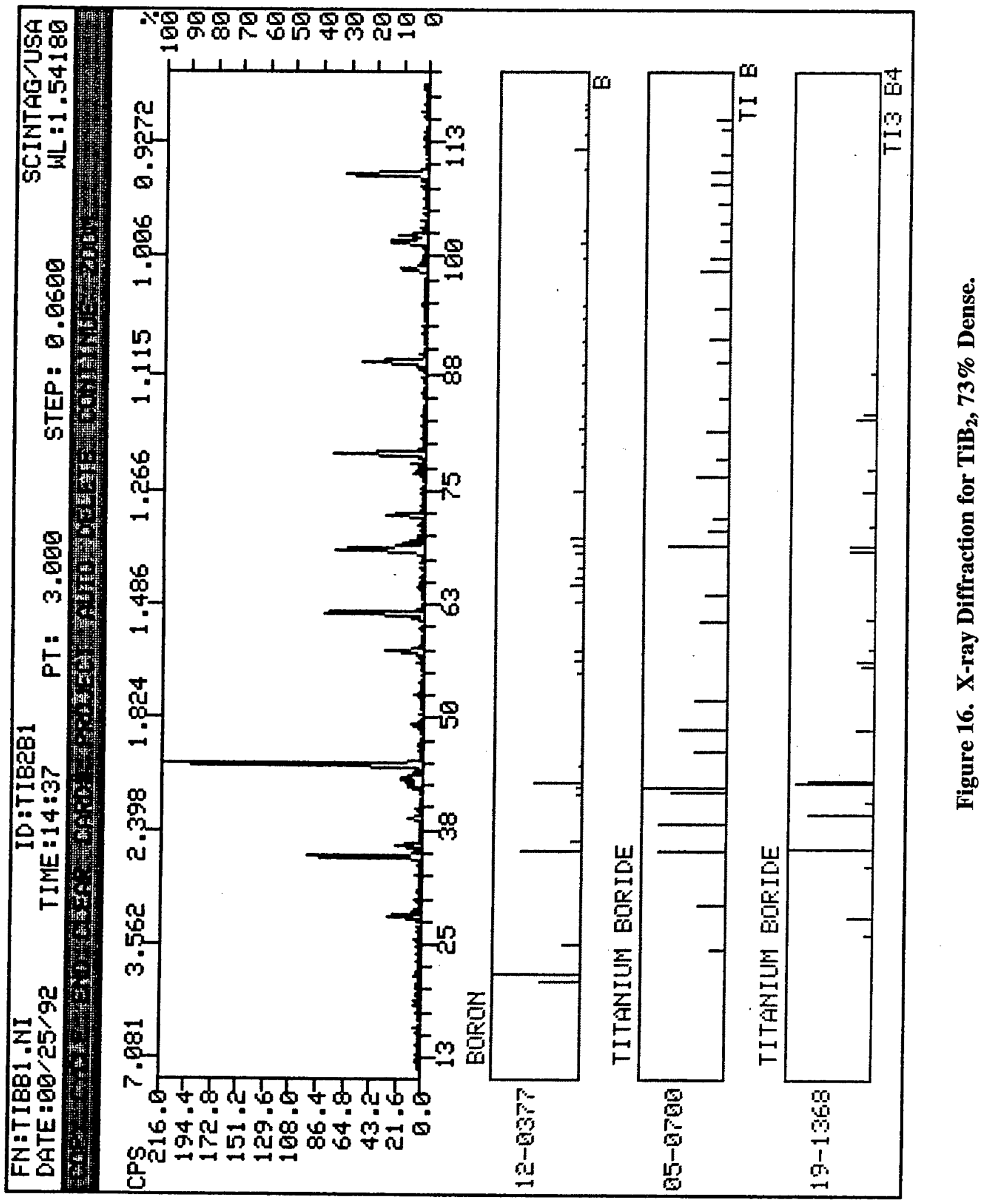




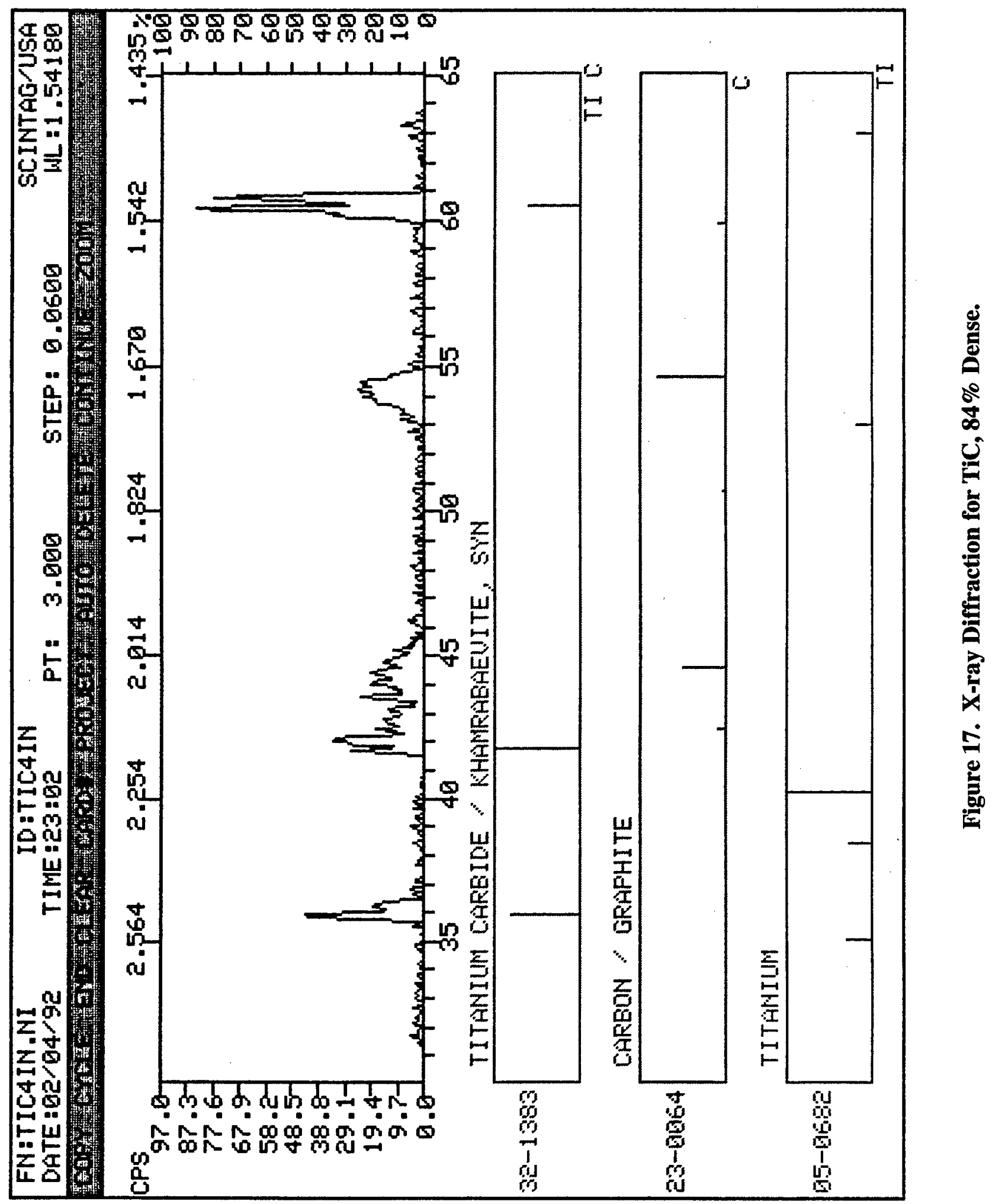


The $\mathrm{TiB}_{2}$ sample is shown in Figure 16. Figure 17 is the pattern for the 10-cm-diameter sample of TiC that was transformed and hot pressed to $84 \%$ density.

5.2 10-cm-Diameter Disk. It was necessary to demonstrate that the controlled SHS approach could be applied to the fabrication of large shapes. The Gleeble 1500 at Rensselaer was employed for the transformation from elemental powders to $\mathrm{TiC}$; $\mathrm{Ni}$ was not used in this sample. It was not possible to densify the $10-\mathrm{cm}$ sample on the Gleeble following transformation because of overheating resulting when running current levels required to densify such a large sample.

The die material was again ordered from Southern Graphite; the dimensions of the die and anvils are shown below. During the current-induced SHS studies, graphite anvils were used to compact the sample; graphite anvils were also used for processing the 10-cm-diameter TiC.

\section{Grade SG-2}

Die: $\quad 12.5-\mathrm{cm} \mathrm{OD} \times 10-\mathrm{cm} \mathrm{ID} \times 8.8-\mathrm{cm}$ long

Anvil: $10-\mathrm{cm} \mathrm{OD} \times 8.8-\mathrm{cm}$ long

A picture of the graphite die and graphite anvils that were used for scale-up to 10-cm diameter is shown in Figure 18.

Powders were weighed out for making two 10-cm-diameter $\mathrm{TiC}$ samples, one $\mathrm{TiC}$ sample with $3 \mathrm{wt} . \% \mathrm{Ni}$, and one $\mathrm{TiB}_{2}$ sample. The mixtures are in Table 3 for the three combinations.

Because of limited availability of the Gleeble 1500 , we were not able to run more than one 10-cm-diameter sample. TiC with no Ni addition was selected for the test. The die was loaded with powder and greened at $14 \mathrm{MPa}$ ( $2 \mathrm{ksi}$ ) before being loaded in the Gleeble. The optical pyrometer was again used to measure the temperature of the graphite die during the test. The graphite anvils were positioned against the powder and again no backing support was placed around the graphite 


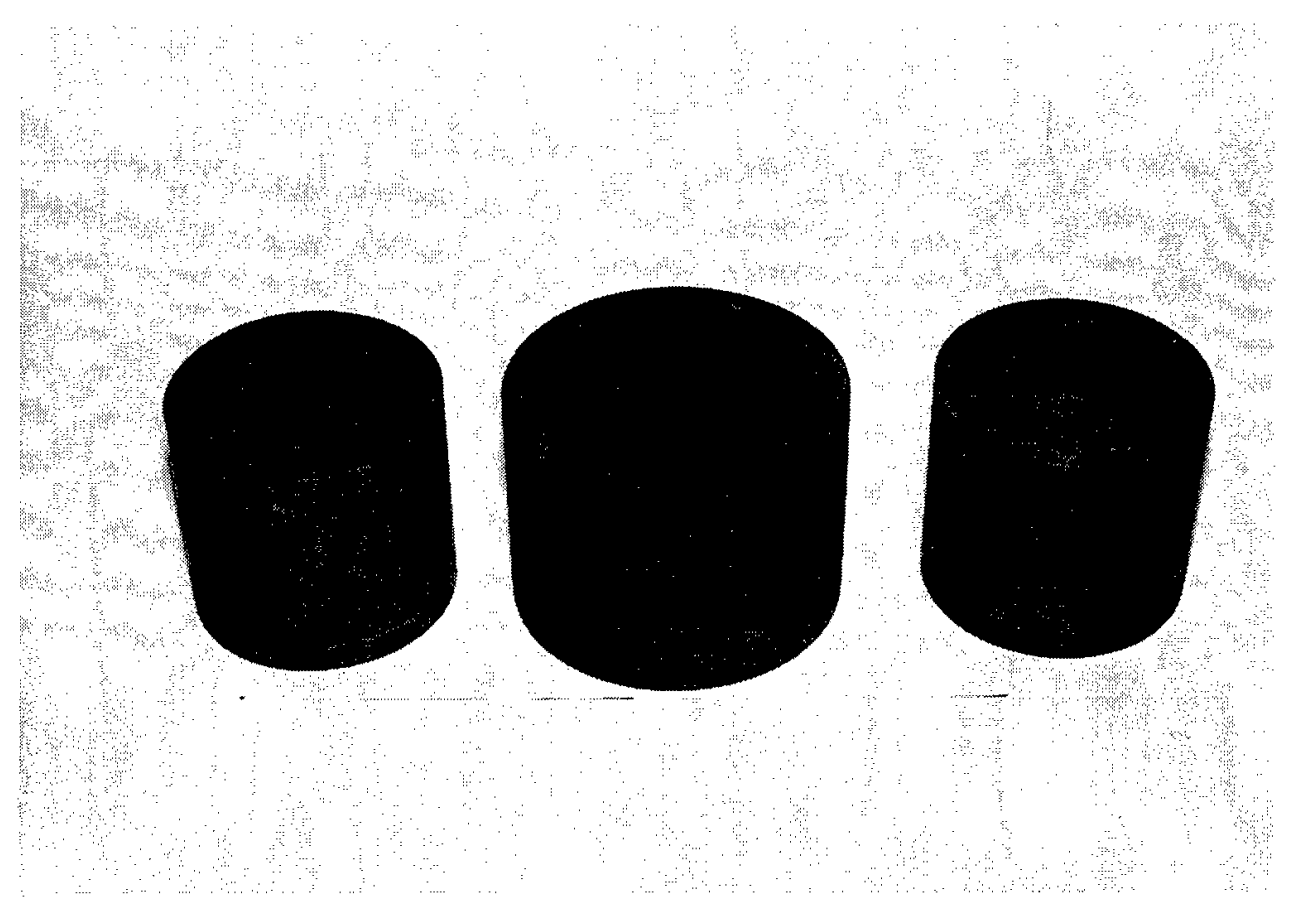

Figure 18. Graphite Die and Anvils for 10-cm Sample.

Table 3. Powder Amounts for Scale-Up to 10-cm-Diameter Sample

\begin{tabular}{|l|c|c|c|c|}
\hline \multirow{2}{*}{ Compound } & \multicolumn{4}{|c|}{ Amount of Powder Added } \\
\cline { 2 - 5 } & $\begin{array}{c}\mathrm{Ti} \\
(\mathrm{g})\end{array}$ & $\begin{array}{c}\mathrm{C} \\
(\mathrm{g})\end{array}$ & $\begin{array}{c}\mathrm{Ni} \\
(\mathrm{g})\end{array}$ & $\begin{array}{c}\mathrm{B} \\
(\mathrm{g})\end{array}$ \\
\hline $\mathrm{TiC}$ & 807.28 & 201.82 & - & - \\
\hline $\mathrm{TiC} / 3$ wt.-\% Ni & 783.06 & 195.77 & 15.13 & - \\
\hline $\mathrm{TiB}_{2}$ & 639.93 & - & - & 290.88 \\
\hline
\end{tabular}

die. The sample was heated slowly to ensure that the powder would not initiate in a self-propagating exothermic manner. The sample began to densify at $700^{\circ} \mathrm{C}$, and the temperature during transformation was as high as $800^{\circ} \mathrm{C}$ with roughly $4,000 \mathrm{~A}$ running through the sample. Pressure on the sample was $2.8 \mathrm{MPa}(0.4 \mathrm{ksi})$. Because of the manner in which the die was positioned in the Gleeble, only the bottom half of the anvil was actually being compressed; use of additional pressure 
would have increased the possibility of having the die rupture. Time for transformation was approximately $30 \mathrm{~min}$, and the density after transformation was 59\%. Figure 13 shows the plot of temperature, load, and stroke change during transformation to TiC. This sample was then taken to General Electric in Schenectady, NY, where it was hot pressed at $2,000^{\circ} \mathrm{C}$ and roughly $21 \mathrm{MPa}$ (3 ksi). At that facility, die design limited pressures to $21 \mathrm{MPa}$. Density after hot pressing was $84 \%$ of theoretical. Data for the hot pressing experiment appear in Table 4.

Table 4. Hot Pressing Data for 10-cm-Diameter Sample

\begin{tabular}{|c|c|c|c|c||}
\hline $\begin{array}{c}\text { Time } \\
(\mathrm{hr}: \mathrm{mm})\end{array}$ & $\begin{array}{c}\text { Temperature } \\
\left({ }^{\circ} \mathrm{C}\right)\end{array}$ & $\begin{array}{c}\text { Deflection } \\
(\mathrm{mm})\end{array}$ & $\begin{array}{c}\text { Pressure } \\
(\mathrm{MPa})\end{array}$ & $\begin{array}{c}\text { Vacuum } \\
(\mu \mathrm{m} \text { of } \mathrm{Hg})\end{array}$ \\
\hline \hline $13: 20$ & - & 0.0 & 0.8 & 8 \\
\hline $14: 05$ & 820 & -1.96 & 0.8 & 16 \\
\hline $14: 25$ & 1,145 & -2.3 & 2.8 & 23 \\
\hline $14: 45$ & 1,420 & -2.1 & 2.8 & 60 \\
\hline $14: 54$ & 1,515 & -1.14 & 5.6 & 110 \\
\hline $15: 24$ & 1,755 & -0.76 & 5.6 & 150 \\
\hline $15: 32$ & 1,775 & -0.78 & 5.6 & 90 \\
\hline $16: 00$ & 1,920 & 0.13 & 5.6 & 48 \\
\hline $16: 22$ & 2,010 & 2.8 & 8.0 & 42 \\
\hline $16: 46$ & 2,050 & 5.5 & 8.0 & 42 \\
\hline
\end{tabular}

Following transformation to $\mathrm{TiC}$ on the Gleeble, the faces of the sample were slightly uneven. As a result, the faces were machined flat at General Electric prior to the hot pressing experiment. The sample was easily machined without cracking and then placed in the graphite die for hot pressing. The sample after hot pressing was cracked, which most likely occurred during cooling. The structure of the $10-\mathrm{cm}$ sample was identical to the $1.25-\mathrm{cm}$-diameter samples in that there were regions of unreacted agglomerated graphite. Ball milling would be applied for future mixing experiments to eliminate these islands of graphite. 


\section{Discussion}

Attempts to achieve high density by initiating the CS reaction with passing current through the sample to provide resistance heating and subsequently dynamically compacting the sample proved unsuccessful. Notable heat loss was reported in the longitudinal direction in comparison with the radial direction of the graphite die that was used for this experiment. Because of this heat loss, adiabatic conditions were not closely approximated such that when pressure was applied, the temperature of the sample was too low to densify to high densities. Densification was limited to $80 \%$ with reactive sintering followed by dynamic compaction.

However, it was found that by passing current through the powder to provide resistance heating, high temperatures are achieved locally and the elemental powders actually do transform to product by a variation of traditional SHS. In this case, pressure was being applied while current was passing through the sample and transformation to product occurred locally without a large exotherm and gas release. This process was termed the slow and steady technique because it provided transformation of reactants to products in a controlled and safe manner. X-ray analysis revealed that the reaction occurred to completion. The current-induced SHS process demonstrated much more control over the transformation than was possible with traditional SHS processing. The transformation rate may be increased by performing the process at a higher current level. But the use of higher current increases the risk of the elemental powders reacting and producing a combustion wave through the remaining unreacted powders. The degassing associated with such a combustion wave will destroy an unsupported graphite die and damage the sample.

In this effort, basically a two-step process was practiced. In the first step, the elemental powders were converted to product, which was roughly $73 \%$ dense after transformation. The second step involved increasing the current level to heat the sample to a temperature sufficient to sinter to high density. Further densification of transformed material was noticed at higher temperatures, such as $1,300^{\circ} \mathrm{C}$. Ni acted not only as a sintering aid but also allowed deformation of the porous material. A creep mechanism led TiC to final high density, such as $97 \%$ of theoretical value. Without $\mathrm{Ni}$ in 
the $\mathrm{Ti}$ and graphite powder mixture, the first step of the process was unchanged but higher temperatures were required for densification. Only $90 \%$ dense material was obtained at temperatures such as $2,200^{\circ} \mathrm{C}$ and under a pressure of $56 \mathrm{MPa}$.

Table 5 shows the A5, A11, A38, A40, A41, and A45 sample densities. Samples A5, A11, and A40 were stopped following transformation; the others were sintered following transformation by increasing the current level. The sintering time needed to go from roughly $70 \%$ density (at $35 \mathrm{MPa}$ ) was on the order of $15 \mathrm{~min}$. A low magnification optical micrograph of sample A5 appears in Figure 19. It shows regions of graphite, which may be attributed to poor mixing. Figures 20 and 21 show the microstructure for sample A38, which is $95 \%$ dense and contains $3 \mathrm{wt} .-\% \mathrm{Ni}$ addition. This microstructure is representative of samples with $\mathrm{Ni}$ addition that were sintered to high density by raising the current level following transformation.

Table 5. Density Measurements (TiC 3 wt.-\% Ni)

\begin{tabular}{|c|l|c|c||}
\hline Sample & \multicolumn{1}{|c|}{ Process Conditions } & $\begin{array}{c}\text { Density } \\
\left(\mathrm{g} / \mathrm{cm}^{3}\right)\end{array}$ & $\begin{array}{c}\text { Theoretical } \\
(\%)\end{array}$ \\
\hline A5 & Transformed at $900^{\circ} \mathrm{C}, 17.5 \mathrm{MPa}$ & 3.52 & 72 \\
\hline A11 & Transformed at $900^{\circ} \mathrm{C}, 35 \mathrm{MPa}$ & 3.68 & 75 \\
\hline A40 & Transformed at $800^{\circ} \mathrm{C}, 35 \mathrm{MPa}$ & 3.47 & 71 \\
\hline A38 & $\begin{array}{l}\text { Transformed at } 800^{\circ} \mathrm{C}, 35 \mathrm{MPa} \\
\text { Sintered at } 1,400^{\circ} \mathrm{C}, 15 \mathrm{~min}, 35 \mathrm{MPa}\end{array}$ & 4.66 & 95 \\
\hline A41 & $\begin{array}{l}\text { Transformed at } 800^{\circ} \mathrm{C}, 35 \mathrm{MPa} \\
\text { Sintered at } 1,400^{\circ} \mathrm{C}, 15 \mathrm{~min}, 35 \mathrm{MPa}\end{array}$ & 4.60 & 94 \\
\hline A45 & $\begin{array}{l}\text { Transformed at } 800^{\circ} \mathrm{C}, 56 \mathrm{MPa} \\
\text { Sintered at } 1,400^{\circ} \mathrm{C}, 15 \mathrm{~min}, 56 \mathrm{MPa}\end{array}$ & 4.76 & 97 \\
\hline
\end{tabular}

In experiments with $\mathrm{Ti}$ and $\mathrm{B}$ powders, transformation of the initial mixture into $\mathrm{TiB}_{2}$ proved that this approach has universal value even though process parameters have to be considered individually for each material. Though not part of this SBIR effort, this approach was also successively demonstrated on the NiAl system. For NiAl, full density was achieved and the sample hardness was comparable to conventionally processed $\mathrm{NiAl}$. 


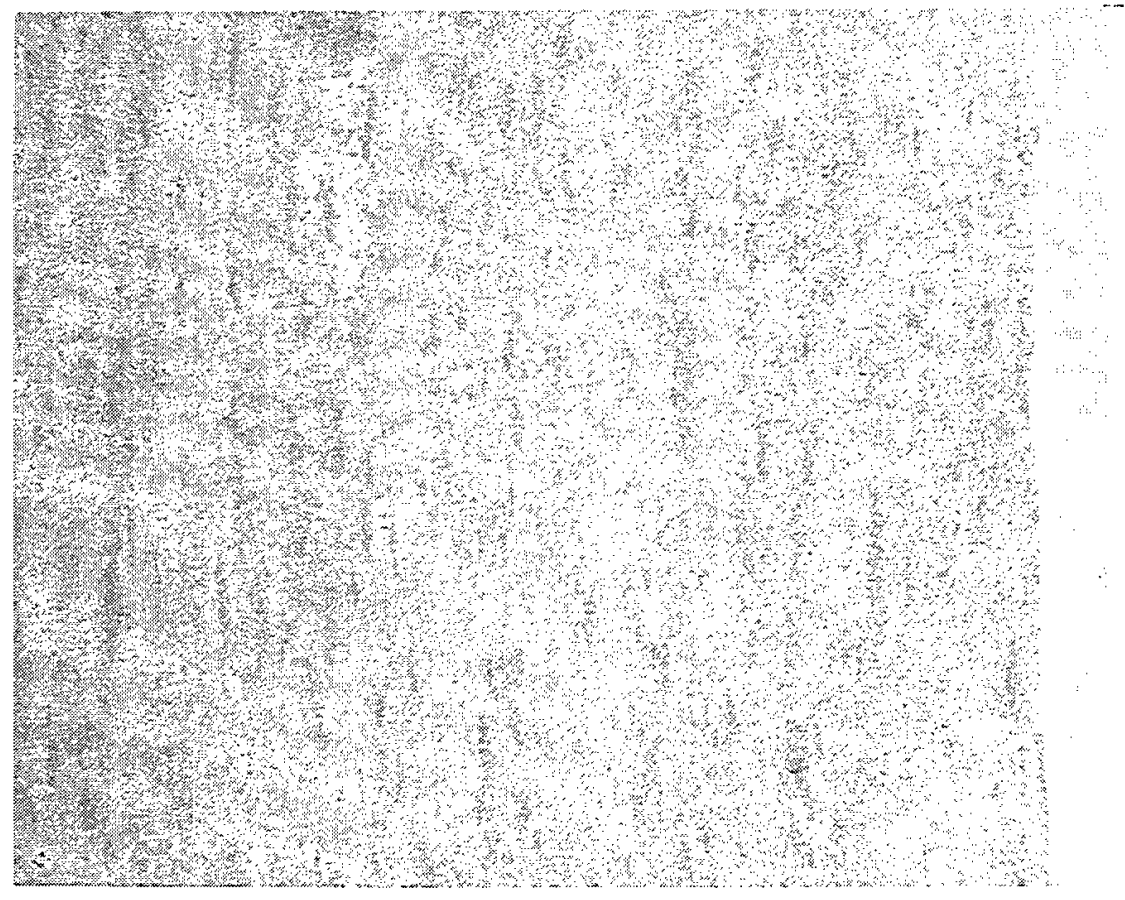

Figure 19. Sample A5 Microstructure, 72\% Dense.
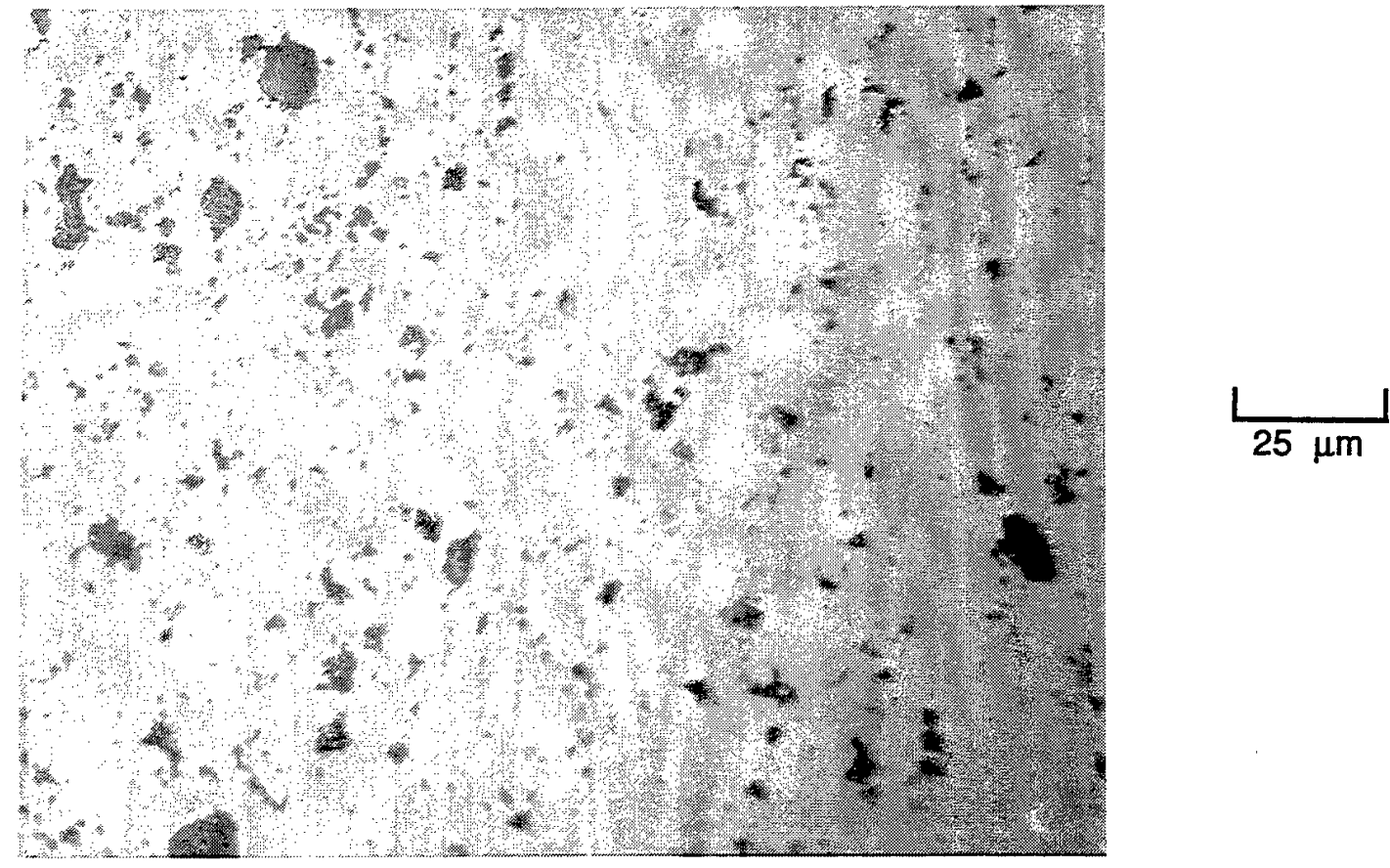

Figure 20. Sample A38 Microstructure, 95\% Dense. 

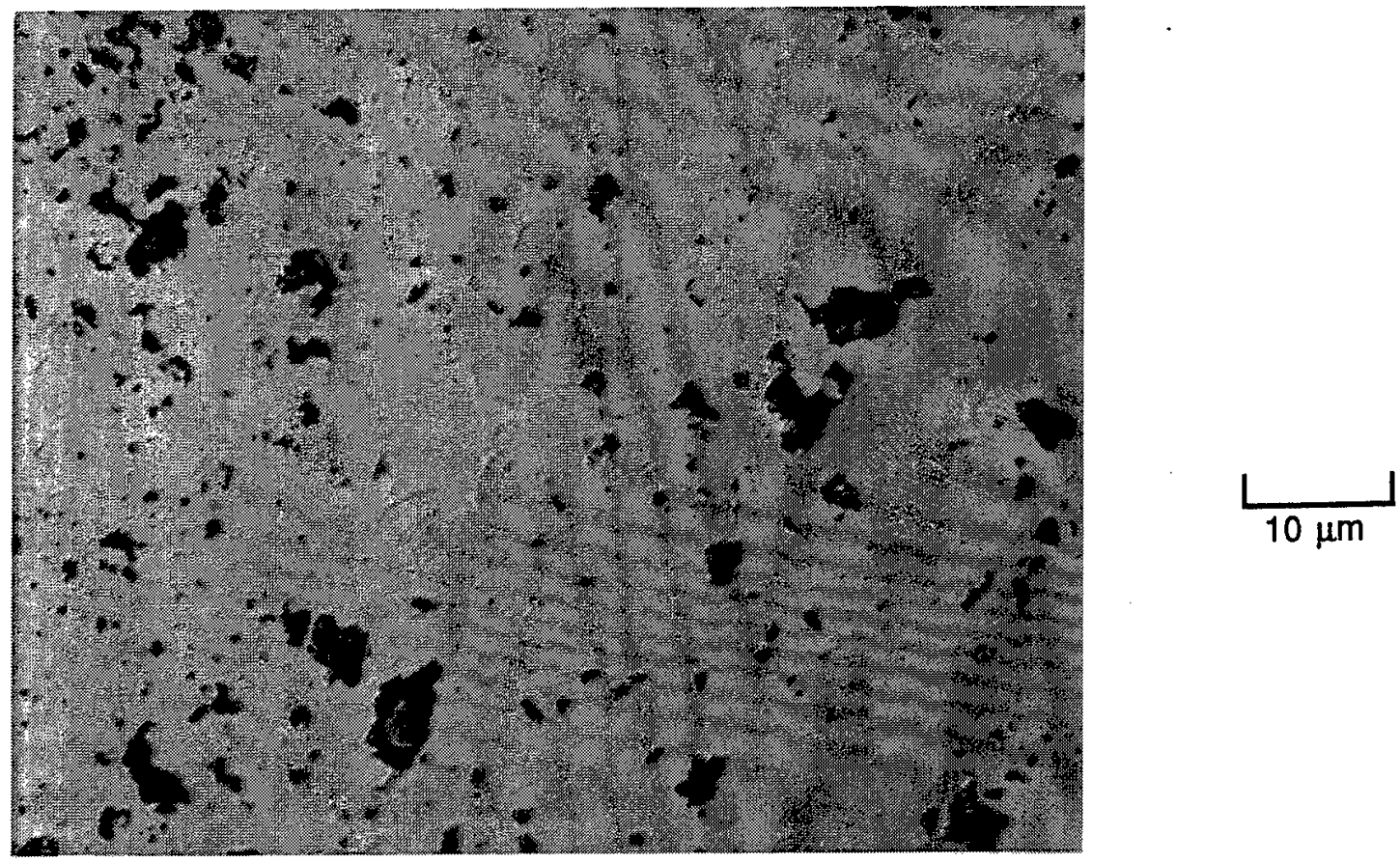

Figure 21. Sample A38 Microstructure, 95\% Dense; Enlarged View.

Additional work that should be performed includes transforming elemental powders with the electrical current technique with a very high stress applied; a test is planned at Duffers Scientific using 700-MPa (100 ksi) pressure during transformation. The goal would be to transform and fully densify in one step. Additionally, the powders for this test would be ball milled to determine whether a more uniform microstructure results.

\section{Summary}

In this effort, an approach employing current-induced reactive sintering was developed and shown to be a viable method for producing $\mathrm{TiC}$ and $\mathrm{TiB}_{2}$ by $\mathrm{CS}$. Applying pressure to a powder mixture of $\mathrm{Ti}$ and $\mathrm{C}$ or $\mathrm{Ti}$ and $\mathrm{B}$, while passing current through the mixture, resulted in the formation of a product by CS with the reaction proceeding in a slow and steady fashion without a large 
exotherm or violent outgassing. This approach demonstrated that CS may be performed while applying pressure to a green compact. Combustion synthesis occurred in a very controlled fashion, and the large exotherm was avoided. In this SBIR effort, the process was demonstrated with $\mathrm{TiC}$, $\mathrm{TiC}$ with $3 \mathrm{wt} .-\% \mathrm{Ni}, \mathrm{TiB}_{2}$, and, to determine the generality of the process, $\mathrm{NiAl}$.

Although it has been shown that excellent shape control is achievable with this technique, further work needs to be performed to assess the effect of pressure during transformation. Specifically, it should be determined whether application of large pressures in the samples will generate $95 \%$ theoretical densities or greater after transformation.

Attempts to obtain high densities using dynamic compaction after reactive sintering were unsuccessful because of large longitudinal heat losses. Renewed attempts to employ current resistance heating to initiate the SHS reaction followed by compaction must focus on a means to prevent large heat losses so that adiabatic conditions are more closely approximated.

The current-induced reactive sintering process may be inexpensively scaled to a manufacturing setup and would not require the same tooling or safety considerations as those for traditional SHS. Further development is required to determine maximum densities that may be achieved as a function of pressure as well as to optimize the process parameters such as current level to reduce the time required to form the synthesized product. 
INTENTIONALLY LEFT BLANK. 


\section{References}

1. German, R. M., A. Bose, and D. M. Sims. "Production of Reactive Sintered Nickel Aluminide Material." U.S. Patent No. 4,762,558, August 1998.

2. Sims, D. M., A. Bose, and R. M. German. "Reactive Sintering of Nickel Aluminide." Progress in Powder Metallurgy. 1987 Annual Powder Metallurgy Conference Proceedings, vol. 43, pp. 575-596, edited by C. L. Freeby and H. Hjort, Metal Powder Industries Federation, Princeton, NJ, 1987.

3. Rabin, B. H., A. Bose, and R. M. German. "Processing Effects on Densification in Reactive Sintering of Nickel-Aluminum Powder Mixtures." Modern Developments in Powder Metallurgy, vol. 19, pp. 511-529, edited by P. U. Gummeson and D. A. Gustafson, Metal Powder Industries Federation, Princeton, NJ, 1988.

4. Bose, A., B. H. Rabin, and R. M. German. "Reactive Sintering Nickel-Aluminide to Near Full Density." Powder Metallurgy International, vol. 20, no. 3, pp. 25-30, September 1988.

5. Munir, Z. A., and U. Anselmi-Tamburini. "Self-Propagating Exothermic Reactions: The Synthesis of High Temperature Materials by Combustion." Materials Science Report, vol. 3, nos. 7-8, pp. 277-365, July-August 1989.

6. Munir, Z. A. "Synthesis of High Temperature Materials by Self-Propagating Combustion Methods." American Ceramic Society Bulletin, vol. 67, no. 2, pp. 342-348, February 1988.

7. Munir, Z. A. "Reactivity of Powders During the Combustion Synthesis of Metallic and Ceramic Powders." Sintering 87, vol. 1, pp. 528-534, edited by S. Somiya, M. Shimada, M. Yoshimura, and R. Watanabe, London, UK: Elsevier Applied Science, 1988.

8. Oddone, R. R., and R. M. German. "Reactive Processing of TiAl for High-Temperature Matrix Composites." Advances in Powder Metallurgy, vol. 3, pp. 475-489, 1989.

9. Holt, J. B., and Z. A. Munir. "Combustion Synthesis of Titanium Carbide: Theory and Experiment." Journal of Materials Science, vol. 21, no. 1, pp. 251-259, January 1986.

10. German, R. M., and A. Bose. "Fabrication of Intermetallic Matrix Composites." Materials Science and Engineering A, vol. 107, no. 1, pp. 107-116, January 1989.

11. Kecskes, L. J., T. Kottke, and A. Niiler. "Microstructural Properties of Combustion-Synthesized and Dynamically-Consolidated Titanium Boride and Titanium Carbide." Journal of the American Ceramic Society, vol. 73, no. 5, pp. 1274-1282, May 1990. 
12. Takeda, S. "Non-oxide Ceramics Sintering by a New Process Thermite Reaction Assisted Sintering and Synthesis Under High Pressure (THP) Process." Sintering 87, vol. 2, pp. 1076-1081, edited by S. Somiya, M. Shimada, M. Yoshimura, and R. Watanabe, Elsevier Applied Science, London, UK, 1988.

13. Sata, N., and J. Ikeuchi. "Application of Synthesis Process by a Self-Propagating Reaction." Sintering 87, vol. 1, pp. 523-527, edited by S. Somiya, M. Shimada, M. Yoshimura, and R. Watanabe, Elsevier Applied Science, London, UK, 1988.

14. Kaieda, Y., M. Otaguchi, O. Odawara, M. Nakamura, T. Oie, and S. Shite. "Self-Propagating High-Temperature Synthesis of Intermetallic Compounds." Sintering 87, vol. 1, pp. 557-562, edited by M. Shimada, M. Yoshimura, and R. Watanabe, Elsevier Applied Science, London, UK, 1988.

15. Richardson, G. Y., R. W. Rice, W. J. McDonough, J. M. Kunetz, and T. Schroeter. "Hot Pressing of Ceramics Using Self-Propagating Synthesis." Ceramic Engineering and Science Proceedings, vol. 7, nos. 7-8, pp. 761-770, July-August 1985.

16. Rice, R. W., W. J. McDonough, G. Y. Richardson, J. M. Kunetz, and T. Schroeter. "Hot Rolling of Ceramics Using Self-Propagating High-Temperature Synthesis." Ceramic Engineering and Science Proceedings, vol. 7, nos. 7-8, pp. 751-760, July-August 1985.

17. Mullins, M. E., and E. Riley. "The Effect of Carbon Morphology on the Combustion Systhesis of Titanium Carbide." Journal of Materials Research, vol. 4, no. 2, pp. 408-411, February 1989.

18. Miyamoto, Y. "New Ceramic Processing Approaches Using Combustion Synthesis Under Gas Pressure." American Ceramic Society Bulletin, vol. 69, no. 4, pp. 686-690, April 1990.

19. Adachi, S., T. Wada, T. Mihara, Y. Miyamoto, M. Koizumi, and O. Yamada. "Fabrication of Titanium Carbide Ceramics by High Pressure Self Combustion Sintering of Titanium Powder and Carbon Fiber." Journal of the American Ceramic Society, vol. 72, no. 5, pp. 805-809, May 1989.

20. Yamada, O., Y. Miyamoto, and M. Koizumi. "High Pressure Self-Combustion Sintering of Titanium Carbide." Journal of the American Ceramic Society, vol. 70, no. 9, pp. C206-C208, September 1987.

21. Misiolek, W. Z., N. D. Sopchak, and R. M. German. "Pressure Assisted Reactive Sintering of $\mathrm{NiAl}_{\text {TiB }}$." Presented at the 1991 TMS Fall Meeting, Cincinnati, OH, 20-24 October 1991.

22. Sopchak, N. D. "Pressure Assisted Reactive Sintering: A New Method of Manufacturing Advanced Materials." Proceedings of the 5th National Conference on Undergraduate Research, University of North Carolina, Asheville, NC, 1991. 
23. German, R. M. "Transient Thermal Effects in the Synthesis of Intermetallic Alloys." To be published.

24. Alman, D. E., and N. S. Stoloff. "Powder Fabrication of Monolithic and Composite NiAl." The International Journal of Powder Metallurgy, vol. 27, no. 1, pp. 29-41, January 1991.

25. Sun, $\mathrm{K}$., and $\mathrm{P}$. Tibbits. "Rapid Resistive Consolidation of $\mathrm{YBa}_{2} \mathrm{Cu}_{3} \mathrm{O}_{7}$ Powder." Journal of Material Shaping Technology, vol. 8, no. 4, pp. 219-223, April 1990. 
INTENTIONALLY LEFT BLANK. 
NO. OF

COPIES ORGANIZATION

2 DEFENSE TECHNICAL INFORMATION CENTER DTIC DDA 8725 JOHN J KINGMAN RD STE 0944

FT BELVOIR VA 22060-6218

1 HQDA

DAMO FDQ

D SCHMIDT

400 ARMY PENTAGON

WASHINGTON DC 20310-0460

$1 \quad$ OSD

OUSD(A\&T)/ODDDR\&E(R)

R J TREW

THE PENTAGON

WASHINGTON DC 20301-7100

1 DPTY CG FOR RDE HQ

US ARMY MATERIEL CMD

AMCRD

MG CALDWELL

5001 EISENHOWER AVE

ALEXANDRIA VA 22333-0001

1 INST FOR ADVNCD TCHNLGY THE UNIV OF TEXAS AT AUSTIN PO BOX 202797

AUSTIN TX 78720-2797

1 DARPA

B KASPAR 3701 N FAIRFAX DR

ARLINGTON VA 22203-1714

1 NAVAL SURFACE WARFARE CTR CODE B07 J PENNELLA

17320 DAHLGREN RD

BLDG 1470 RM 1101

DAHLGREN VA $22448-5100$

1 US MILITARY ACADEMY MATH SCI CTR OF EXCELLENCE DEPT OF MATHEMATICAL SCI MAJ M D PHILLIPS

THAYER HALL

WEST POINT NY 10996-1786
NO. OF

COPIES ORGANIZATION

1 DIRECTOR

US ARMY RESEARCH LAB

AMSRL D

R W WHALIN

2800 POWDER MILL RD

ADELPHI MD 20783-1145

1 DIRECTOR

US ARMY RESEARCH LAB

AMSRL DD

J J ROCCHIO

2800 POWDER MILL RD

ADELPHI MD 20783-1145

1 DIRECTOR

US ARMY RESEARCH LAB

AMSRL CS AS (RECORDS MGMT)

2800 POWDER MILL RD

ADELPHI MD 20783-1145

3 DIRECTOR

US ARMY RESEARCH LAB

AMSRL CI LL

2800 POWDER MILL RD

ADELPHI MD 20783-1145

ABERDEEN PROVING GROUND

4 DIR USARL

AMSRL CI LP (305) 
NO. OF

COPIES ORGANIZATION

2 US ARMY ARDEC

D KAPOOR

S CYTRON

DOVER NJ 07801

3 ARMY RESEARCH OFFICE

A CROWSON

E CHEN

R REEBER

PO BOX 12211

RSRCH TRIANGLE PARK NC

27709-2211

1 BATTELLE PACIFIC NW

LABORATORIES

W GURWELL

PO BOX 999

RICHLAND WA 99352

1 PENNSYLVANIA STATE UNTV

DEPT ENGNR SCIENCES AND

MECHANICS

R GERMAN

227 HAMMOND BLDG

UNIVERSITY PARK PA

16802-1401

1 UNIV OF CALIFORNIA

SAN DIEGO

DEPT APPLIED MECHANICS

AND ENGNR SCIENCES

M MEYERS

MAIL CODE 0411

9500 GILMAN DRIVE

LA JOLLA CA 92093-0411

2 GEORGIA INST OF TECH

SCHL OF MTRL ENG

K LOGAN

N THADANI

ATLANTA GA 30332-0245

3 NEW MEXICO INST

OF MINING AND TECH

CTR FOR EXPLSV TECH \& RSRCH

A MILLER

P PERSSON

MTRLS AND MET ENG

O INAL

SOCORRO NM 87801
NO. OF

COPIES ORGANIZATION

1 UNIV OF CALIFORNIA

COLLEGE OF ENGNRNG

Z MUNIR

DAVIS CA 95616

\section{ABERDEEN PROVING GROUND}

30 DIR USARL

AMSRL WM TE

L KECSKES (15 CPS)

A NIILER

AMSRL WM TA

W GOOCH

W GILLICH

M BURKINS

G HAUVER

T HAVEL

E HORWATH

AMSRL WM TD

$K$ FRANK

AMSRL WM TC

E KENNEDY

L MAGNESS

AMSRL WM MC

J LASALVIA

T HYNES

J MCCAULEY

D VIECHNICKI

J WELLS 


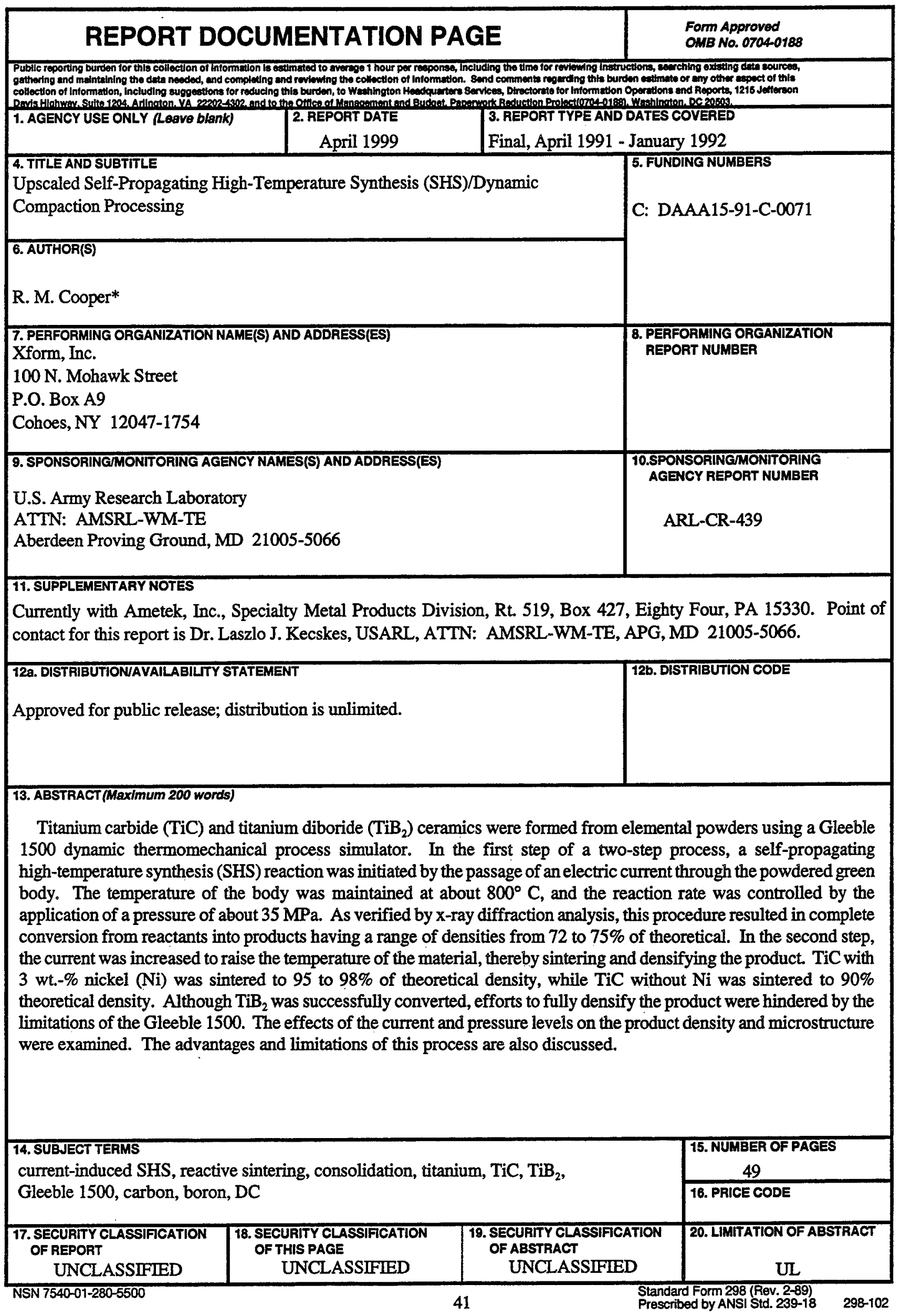


INTENTIONALLY LEFT BLANK。 


\section{USER EVALUATION SHEET/CHANGE OF ADDRESS}

This Laboratory undertakes a continuing effort to improve the quality of the reports it publishes. Your comments/answers to the items/questions below will aid us in our efforts.

1. ARL Report Number/Author__ARL-CR-439 (Cooper [Kecskes]) Date of Report April 1999

2. Date Report Received

3. Does this report satisfy a need? (Comment on purpose, related project, or other area of interest for which the report will be used.)

4. Specifically, how is the report being used? (Information source, design data, procedure, source of ideas, etc.)

5. Has the information in this report led to any quantitative savings as far as man-hours or dollars saved, operating costs avoided, or efficiencies achieved, etc? If so, please elaborate.

6. General Comments. What do you think should be changed to improve future reports? (Indicate changes to organization, technical content, format, etc.)

\section{Organization}

CURRENT

ADDRESS

Name E-mail Name

Street or P.O. Box No.

City, State, Zip Code

7. If indicating a Change of Address or Address Correction, please provide the Current or Correct address above and the Old or Incorrect address below.

OLD

ADDRESS
Organization

Name

Street or P.O. Box No.

City, State, Zip Code

(Remove this sheet, fold as indicated, tape closed, and mail.) 
DEPARTMENT OF THE ARMY

OFFCIAL BUSINESS

\section{BUSINESS REPLY MAIL}

FIRST CLASS PERMIT NO 0001,APG,MD

NO POSTAGE

NECESSARY

IF MAILED

IN THE

UNITED STATES

POSTAGE WILL BE PAID BY ADDRESSEE

DIRECTOR

US ARMY RESEARCH LABORATORY

ATTN AMSRL WM TE

ABERDEEN PROVING GROUND MD 21005-5066 